Supporting information

\title{
Activation Mechanism of Corticotrophin Releasing Factor Receptor Type 1 Elucidated Using Molecular Dynamics Simulations
}

\author{
Abdullahi Ibrahim $\mathrm{Uba}^{1 \S}$, Nicolas Scorese ${ }^{\S}$, Emily Dean ${ }^{2}$, Haiguang Liu ${ }^{1 *}$ and Chun $\mathrm{Wu}^{2 *}$
}

Complex Systems Division, Beijing Computational Science Research Center, Beijing 100193, China

${ }^{2}$ College of Science and Mathematics, Rowan University, Glassboro, NJ, 08028 USA

a: Both authors contributed equally to this work

* To whom correspondence should be addressed: Chun Wu: wuc@ rowan.edu;

Haiguang Liu:hgliu@csrc.ac.cn 
Table S1. Mean RMSF values of the specific regions of CRF1R averaged over 2 trajectories for apo CRF1R and over 3 trajectories for agonist bound CRF1R and antagonist bound CRF1R (1000 ns each).

\begin{tabular}{ccc}
\hline Region & RMSF of CRF1R-Urocortin 1 (̊) & RMSF of CRF1R-CP-376395 (̊̊) \\
\hline N-terminus & 6.5 & 8.0 \\
TM1 & 5.1 & 5.21 \\
I1 & 5.5 & 3.9 \\
TM2 & 3.1 & 3.8 \\
E1 & 5.4 & 4.7 \\
TM3 & 3.4 & 3.4 \\
I2 & 5.8 & 5.3 \\
TM4 & 2.8 & 3.8 \\
E2 & 4.6 & 4.9 \\
TM5 & 3.8 & 4.4 \\
I3 & 7.2 & 6.8 \\
TM6 & 3.3 & 4.7 \\
E3 & 6.5 & 5.3 \\
TM7 & 4.1 & 4.5 \\
C-terminus & 6.7 & 8.9 \\
All Is & 6.2 & 5.4 \\
All Es & 5.5 & 5.0 \\
All Loops & 5.8 & 5.2 \\
All TMs & 3.6 & 4.3 \\
Overall & 5.1 & 6.1 \\
\hline
\end{tabular}

The mean RMSF values were computed over the average of 3 trajectories for each system. 
Table S2. Interaction between CRF1R and peptide agonist urocortin 1 over three trajectories (1000 ns long each)

\begin{tabular}{|c|c|c|c|c|}
\hline Interaction & Percentage & Fraction & Generic Number & Location \\
\hline D27-R30 & 82.03 & 0.82 & & $\mathrm{~N}$-terminal ECD \\
\hline D298-D2 & 66.50 & 0.67 & $5.36 \times 37$ & TM5 \\
\hline LYS11-E20 & 64.43 & 0.64 & & N-terminal ECD \\
\hline K291-ASP2 & 57.40 & 0.57 & & ECL2 \\
\hline R57-V41 & 43.93 & 0.44 & & $\mathrm{~N}$-terminal ECD \\
\hline Q26-Q27 & 39.83 & 0.40 & & $\mathrm{~N}$-terminal ECD \\
\hline R85-D39 & 33.33 & 0.33 & & N-terminal ECD \\
\hline D27-Q27 & 32.00 & 0.32 & & $\mathrm{~N}$-terminal ECD \\
\hline A23-Q27 & 30.60 & 0.31 & & $\mathrm{~N}$-terminal ECD \\
\hline Y224-S7 & 41.73 & 0.42 & $4.66 \times 66$ & TM4 \\
\hline S47-D39 & 26.63 & 0.27 & & $\mathrm{~N}$-terminal ECD \\
\hline E104-R35 & 25.10 & 0.25 & & $\mathrm{~N}$-terminal ECD \\
\hline E365-D2 & 23.47 & 0.23 & & ECL3 \\
\hline Q26-N34 & 23.10 & 0.23 & & $\mathrm{~N}$-terminal ECD \\
\hline N45-F38 & 22.87 & 0.23 & & $\mathrm{~N}$-terminal ECD \\
\hline E365-N3 & 21.60 & 0.22 & & ECL3 \\
\hline L33-S40 & 19.03 & 0.19 & & N-terminal ECD \\
\hline V21-Q27 & 18.27 & 0.18 & & N-terminal ECD \\
\hline R8-R23 & 18.00 & 0.18 & & $\mathrm{~N}$-terminal ECD \\
\hline S40-V41 & 17.13 & 0.17 & & $\mathrm{~N}$-terminal ECD \\
\hline Y124-R23 & 16.93 & 0.17 & & $\mathrm{~N}$-terminal ECD \\
\hline D27-R23 & 16.87 & 0.17 & & N-terminal ECD \\
\hline Q302-D2 & 15.80 & 0.16 & $5.40 \times 40$ & TM5 \\
\hline V48-N34 & 15.70 & 0.16 & & $\mathrm{~N}$-terminal ECD \\
\hline E31-R30 & 15.23 & 0.15 & & N-terminal ECD \\
\hline A46-R35 & 14.20 & 0.14 & & $\mathrm{~N}$-terminal ECD \\
\hline E108-R35 & 13.23 & 0.13 & & $\mathrm{~N}$-terminal ECD \\
\hline N19-E20 & 13.03 & 0.13 & & N-terminal ECD \\
\hline D49-R35 & 12.73 & 0.13 & & $\mathrm{~N}$-terminal ECD \\
\hline Y124-R16 & 12.70 & 0.13 & & $\mathrm{~N}$-terminal ECD \\
\hline D298-N3 & 12.17 & 0.12 & $5.36 \times 37$ & TM5 \\
\hline C30-N34 & 11.97 & 0.12 & & $\mathrm{~N}$-terminal ECD \\
\hline Q26-S26 & 11.67 & 0.12 & & $\mathrm{~N}$-terminal ECD \\
\hline W288-R16 & 10.93 & 0.11 & $45.51 \times 51$ & ECL2 \\
\hline D156-S7 & 10.93 & 0.11 & & $\mathrm{~N}$-terminal ECD \\
\hline E381-S7 & 10.80 & 0.11 & $7.46 \times 46$ & TM7 \\
\hline Q302-N3 & 10.80 & 0.11 & $5.40 \times 40$ & TM5 \\
\hline N362-N3 & 10.57 & 0.11 & & ECL3 \\
\hline Y116-R28 & 10.47 & 0.10 & & $\mathrm{~N}$-terminal ECD \\
\hline E109-R35 & 10.40 & 0.10 & & $\mathrm{~N}$-terminal ECD \\
\hline R194-L6 & 10.00 & 0.10 & & ICL2 \\
\hline E381-S5 & 9.83 & 0.10 & $7.46 \times 46$ & TM7 \\
\hline
\end{tabular}




\begin{tabular}{|c|c|c|c|c|}
\hline Y299-S5 & 9.07 & 0.09 & $5.37 \times 38$ & TM5 \\
\hline F359-N3 & 8.87 & 0.09 & $6.56 \times 56$ & TM6 \\
\hline G126-H13 & 8.67 & 0.09 & & $\mathrm{~N}$-terminal ECD \\
\hline E109-R28 & 8.50 & 0.09 & & N-terminal ECD \\
\hline H117-N25 & 8.20 & 0.08 & & N-terminal ECD \\
\hline Q302-S5 & 8.07 & 0.08 & $5.40 \times 40$ & TM5 \\
\hline F289-D2 & 7.90 & 0.08 & $45.52 \times 52$ & ECL2 \\
\hline E109-R30 & 7.83 & 0.08 & & $\mathrm{~N}$-terminal ECD \\
\hline N19-E23 & 7.67 & 0.08 & & $\mathrm{~N}$-terminal ECD \\
\hline Q6-Q27 & 7.50 & 0.08 & & N-terminal ECD \\
\hline L13-R23 & 7.40 & 0.07 & & $\mathrm{~N}$-terminal ECD \\
\hline E31-N34 & 6.33 & 0.06 & & $\mathrm{~N}$-terminal ECD \\
\hline I122-E20 & 6.33 & 0.06 & & $\mathrm{~N}$-terminal ECD \\
\hline D49-R28 & 6.13 & 0.06 & & $\mathrm{~N}$-terminal ECD \\
\hline Q202-T11 & 6.07 & 0.06 & $2.68 \times 68$ & TM2 \\
\hline E208-Q25 & 6.00 & 0.06 & & ECL1 \\
\hline E381-N3 & 5.60 & 0.06 & $7.46 \times 46$ & TM7 \\
\hline N123-T17 & 5.50 & 0.06 & & $\mathrm{~N}$-terminal ECD \\
\hline E208-R23 & 5.30 & 0.05 & & ECL1 \\
\hline C128-L10 & 5.17 & 0.05 & & $\mathrm{~N}$-terminal ECD \\
\hline N123-R16 & 5.07 & 0.05 & & $\mathrm{~N}$-terminal ECD \\
\hline A46-V41 & 4.90 & 0.05 & & $\mathrm{~N}$-terminal ECD \\
\hline N19-L19 & 4.80 & 0.05 & & $\mathrm{~N}$-terminal ECD \\
\hline Y124-R28 & 4.70 & 0.05 & & $\mathrm{~N}$-terminal ECD \\
\hline S378-S5 & 4.70 & 0.05 & $7.43 \times 42$ & TM7 \\
\hline Q26-R30 & 4.60 & 0.05 & & N-terminal ECD \\
\hline E101-R35 & 4.53 & 0.05 & & N-terminal ECD \\
\hline S100-R35 & 4.10 & 0.04 & & $\mathrm{~N}$-terminal ECD \\
\hline A23-R30 & 4.00 & 0.04 & & $\mathrm{~N}$-terminal ECD \\
\hline E285-D2 & 3.93 & 0.04 & & ECL2 \\
\hline K11-T17 & 3.57 & 0.04 & & $\mathrm{~N}$-terminal ECD \\
\hline F289-R16 & 3.53 & 0.04 & $45.52 \times 52$ & ECL2 \\
\hline S47-R34 & 3.53 & 0.04 & & $\mathrm{~N}$-terminal ECD \\
\hline Q103-D39 & 3.43 & 0.03 & & $\mathrm{~N}$-terminal ECD \\
\hline Y299-D2 & 3.27 & 0.03 & $5.37 \times 38$ & TM5 \\
\hline E367-R16 & 3.27 & 0.03 & & ECL3 \\
\hline Y301-D2 & 3.10 & 0.03 & $5.39 \times 39$ & TM5 \\
\hline W93-D39 & 3.10 & 0.03 & & $\mathrm{~N}$-terminal ECD \\
\hline Q211-L18 & 2.83 & 0.03 & & ECL1 \\
\hline S100-V41 & 2.70 & 0.03 & & $\mathrm{~N}$-terminal ECD \\
\hline N45-S40 & 2.70 & 0.03 & & $\mathrm{~N}$-terminal ECD \\
\hline H127-H13 & 2.67 & 0.03 & & N-terminal ECD \\
\hline W93-F38 & 2.67 & 0.03 & & $\mathrm{~N}$-terminal ECD \\
\hline D27-Q33 & 2.60 & 0.03 & & N-terminal ECD \\
\hline Q26-T24 & 2.57 & 0.03 & & $\mathrm{~N}$-terminal ECD \\
\hline
\end{tabular}




\begin{tabular}{ccccc} 
Y224-I8 & 2.57 & 0.03 & $4.66 \times 66$ & TM4 \\
D27-N34 & 2.53 & 0.03 & & N-terminal ECD \\
N45-V41 & 2.50 & 0.03 & N-terminal ECD \\
S130-P4 & 2.43 & 0.02 & N-terminal ECD \\
R57-S40 & 2.33 & 0.02 & N-terminal ECD \\
S22-N3 & 2.30 & 0.02 & N-terminal ECD \\
N45-D39 & 2.23 & 0.02 & N-terminal ECD \\
L125-R23 & 2.10 & 0.02 & N-terminal ECD \\
N19-S26 & 2.00 & 0.02 & N-terminal ECD \\
\hline
\end{tabular}


Table S3. Mean values for residue distance. Distances 1, 3,7-11 and 20 (yellow) show increasing trend in the agonist urocortin 1-bound CRF1R. Distance 4 and 5 (cyan) show decreasing trend in the agonist urocortin 1 bound CRF1R. The rest of the residue distances do not show clear trends even though some of them have higher mean values in the agonist urocortin 1-bound CRF1R when compared to the antagonist CP-376395 bound CRF1R.

\begin{tabular}{|c|c|c|c|c|c|c|c|}
\hline \multirow{2}{*}{$\begin{array}{c}\text { Index } \\
\text { No. }\end{array}$} & \multirow[b]{2}{*}{ Distance $(\AA)$} & \multicolumn{3}{|c|}{ Agonist urocortin 1 bound CRF1R } & \multicolumn{3}{|c|}{ Antagonist CP-376395 bound CRF1R } \\
\hline & & $1000 \mathrm{~ns}$ & First $100 \mathrm{~ns}$ & Last $100 \mathrm{~ns}$ & $1000 \mathrm{~ns}$ & First $100 \mathrm{~ns}$ & Last $100 \mathrm{~ns}$ \\
\hline 1 & $\mathrm{R} 180^{2.46}: \mathrm{E} 238^{3.50}$ & $6.9 \pm 0.4$ & $7.5 \pm 0.9$ & $6.7 \pm 0.3$ & $3.3 \pm 0.9$ & $5.4 \pm 0.9$ & $2.6 \pm 0.6$ \\
\hline 2 & $\mathrm{H} 184^{2.50}: \mathrm{E} 238^{3.50}$ & $2.7 \pm 0.4$ & $2.2 \pm 0.0$ & $3.64 \pm 0.3$ & $2.4 \pm 0.5$ & $2.1 \pm 0.4$ & $4.2 \pm 0.1$ \\
\hline 3 & $\mathrm{~S} 333^{6.30}: \mathrm{L} 395^{7.60}$ & $19.3 \pm 1.8$ & $17.3 \pm 1.3$ & $20.8 \pm 2.9$ & $16.7 \pm 1.2$ & $17.1 \pm 0.4$ & $17.21 \pm 0.2$ \\
\hline 4 & $\mathrm{~F} 232^{3.44}: \mathrm{Y}^{2} 36^{6.53}$ & $8.5 \pm 0.2$ & $9.8 \pm 0.4$ & $10.7 \pm 0.4$ & $14.0 \pm 0.4$ & $9.2 \pm 0.3$ & $10.4 \pm 0.5$ \\
\hline 5 & $\mathrm{H} 228^{3.40}: \mathrm{Y}^{3} 6^{6.53}$ & $12.2 \pm 0.2$ & $8.1 \pm 0.3$ & $8.04 \pm 0.1$ & $13.0 \pm 0.3$ & $9.7 \pm 0.3$ & $9.9 \pm 0.2$ \\
\hline 6 & $\mathrm{~N} 312^{5.50}: \mathrm{Y}_{356^{6.53}}$ & $10.9 \pm 0.2$ & $10.5 \pm 0.2$ & $11.1 \pm 0.2$ & $12.1 \pm 0.2$ & $12.0 \pm 0.2$ & $12.2 \pm 0.2$ \\
\hline 7 & $\mathrm{R} 180^{2.46}: \mathrm{E} 398^{\mathrm{H} 8}$ & $11.9 \pm 0.7$ & $8.4 \pm 1.4$ & $13.3 \pm 0.7$ & $3.9 \pm 0.4$ & $4.2 \pm 0.6$ & $3.8 \pm 0.8$ \\
\hline 8 & D156 $6^{1.76}: R 194^{2.60}$ & $12.8 \pm 2.3$ & $3.7 \pm 1.2$ & $14.2 \pm 0.6$ & $4.5 \pm 0.6$ & $3.6 \pm 0.5$ & $5.4 \pm 0.9$ \\
\hline 9 & $\mathrm{D} 283^{4.68}: \mathrm{R} 292^{\mathrm{ECL} 2}$ & $6.1 \pm 1.0$ & $5.8 \pm 0.6$ & $8.2 \pm 0.8$ & $3.5 \pm 0.4$ & $4.1 \pm 0.9$ & $3.4 \pm 0.5$ \\
\hline 10 & $\mathrm{E} 285^{\mathrm{ECL} 2}: \mathrm{R} 292^{\mathrm{ECL} 2}$ & $8.60 \pm 1.31$ & $7.8 \pm 1.1$ & $12.5 \pm 1.3$ & $5.0 \pm 0.4$ & $4.6 \pm 0.8$ & $5.7 \pm 0.6$ \\
\hline 11 & K291 ${ }^{\text {ECL2}: D 298 ~}{ }^{5.36}$ & $7.35 \pm 1.23$ & $7.3 \pm 0.9$ & $11.8 \pm 3.1$ & $5.3 \pm 0.6$ & $6.6 \pm 1.0$ & $4.3 \pm 0.7$ \\
\hline 12 & D366 ${ }^{\mathrm{ECL} 3}: \mathrm{R} 370^{7.35}$ & $6.71 \pm 1.21$ & $7.0 \pm 1.0$ & $7.5 \pm 1.0$ & $8.9 \pm 1.8$ & $6.1 \pm 0.6$ & $8.7 \pm 0.5$ \\
\hline 13 & $\mathrm{E} 208^{\mathrm{ECL} 1}: \mathrm{K} 286^{\mathrm{ECL} 2}$ & $18.2 \pm 2.1$ & $20.2 \pm 2.4$ & $19.3 \pm 2.6$ & $13.8 \pm 1.1$ & $14.3 \pm 0.8$ & $16.8 \pm 0.6$ \\
\hline 14 & $\mathrm{R} 218^{3.30}: \mathrm{E} 285^{\mathrm{ECL} 2}$ & $11.6 \pm 2.8$ & $11.0 \pm 2.8$ & $11.7 \pm 1.4$ & $12.5 \pm 2.6$ & $13.9 \pm 2.4$ & $11.7 \pm 2.9$ \\
\hline 15 & $\mathrm{R} 173^{\mathrm{ICL} 1}: \mathrm{E} 398^{\mathrm{H} 8}$ & $10.5 \pm 0.0$ & $12.2 \pm 0.5$ & $8.4 \pm 2.8$ & $10.5 \pm 2.3$ & $12.8 \pm 0.9$ & $7.0 \pm 2.3$ \\
\hline 16 & $\mathrm{~K} 291^{\mathrm{ECL} 2}: \mathrm{E} 367^{7.32}$ & $15.5 \pm 2.2$ & $15.4 \pm 1.9$ & $15.3 \pm 1.2$ & $9.6 \pm 1.7$ & $5.0 \pm 1.0$ & $10.8 \pm 3.1$ \\
\hline 17 & $\mathrm{R} 194^{2.60}: \mathrm{E} 381^{7.46}$ & $8.4 \pm 0.5$ & $9.0 \pm 0.3$ & $7.8 \pm 1.0$ & $5.7 \pm 0.2$ & $3.4 \pm 0.21$ & $5.9 \pm 0.6$ \\
\hline 18 & $\mathrm{D} 156^{1.76}: \mathrm{Q} 202^{2.68}$ & $10.0 \pm 0.7$ & $9.2 \pm 0.8$ & $10.3 \pm 0.4$ & $11.0 \pm 0.6$ & $11.1 \pm 1.0$ & $11.5 \pm 06$ \\
\hline 19 & $\mathrm{E} 160^{1.76}: \mathrm{N} 195^{2.61}$ & $6.2 \pm 0.5$ & $5.8 \pm 1.2$ & $5.8 \pm 0.8$ & $4.3 \pm 0.3$ & $4.5 \pm 0.6$ & $3.9 \pm 0.3$ \\
\hline 20 & $\mathrm{Y} 356^{6.53}: \mathrm{Q} 384^{7.49}$ & $11.0 \pm 0.7$ & $9.5 \pm 2.2$ & $10.5 \pm 1.0$ & $4.8 \pm 0.25$ & $5.2 \pm 0.6$ & $4.8 \pm 0.4$ \\
\hline 21 & $\mathrm{~N} 362^{\mathrm{ECL} 3}: \mathrm{R} 370^{7.35}$ & $7.4 \pm 0.7$ & $5.4 \pm 0.5$ & $8.5 \pm 0.6$ & $7.4 \pm 0.7$ & $7.9 \pm 1.5$ & $5.7 \pm 0.9$ \\
\hline
\end{tabular}

Note: Distances 1 and 7-17 were measured between O and N. Distances 3-6 were measured between the center of mass of the residue pairs Distances 18 to 21 are measured between $\mathrm{NH}$ and $\mathrm{O}$ and between $\mathrm{OH}$ and $\mathrm{N}$. N312.50 is $86 \%$ conserved in class $\mathrm{B}$ and subfamily B 1 of class B GPCRs. R180 $2.46, \mathrm{H} 184^{2.50}$, E238 $38^{3.50}$ and Q384.49 are 83\% conserved in class B and subfamily B 1 of class B GPCRs. R194 ${ }^{2.60}$, Y356 $6^{6.53}$, and $\mathrm{E} 398^{\mathrm{H} 8}$ are $66 \%, 72 \%$, and $83 \%$ conserved, respectively, in Subfamily B 1 of class B GPCRs. Y356 ${ }^{6.53}$, Q3847.49, and L3957.60 are critical residues identified by network analysis that overlap with mutagenesis data. K291 ${ }^{\mathrm{ECL} 2}$ is a key interacting residue (Occupancy: > 80\%) that overlap with mutagenesis data. 
Table S4. Conserved residues ( $\geq 83 \%$ ) in PFAM SEED sequences of class B GPCRs in CRF1R and in subfamily B 1 GPCRs (Blue). Conserved residues ( $\geq 83 \%$ ) in subfamily B 1 GPCRs only (Green). Critical nodes (residues) from the network analysis overlapping with the conserved residues are indicated using TICK $(\checkmark)$ sign.

\begin{tabular}{|c|c|c|c|c|}
\hline Residue & Percentage identity (\%) & $\begin{array}{l}\text { Generic } \\
\text { number }\end{array}$ & Location & $\begin{array}{l}\text { Overlap with critical } \\
\text { residue from } \\
\text { network analysis }\end{array}$ \\
\hline $\mathrm{C} 44$ & 100 & & N-terminal ECD & $\checkmark$ \\
\hline D49 & 100 & & N-terminal ECD & $\checkmark$ \\
\hline C54 & 100 & & N-terminal ECD & \\
\hline W55 & 100 & & N-terminal ECD & \\
\hline P56 & 100 & & N-terminal ECD & \\
\hline G61 & 100 & & N-terminal ECD & \\
\hline C68 & 100 & & N-terminal ECD & \\
\hline P69 & 100 & & N-terminal ECD & \\
\hline $\mathrm{C} 87$ & 100 & & N-terminal ECD & \\
\hline G91 & 100 & & N-terminal ECD & \\
\hline $\mathrm{C} 102$ & 100 & & N-terminal ECD & \\
\hline G126 & 93 & & N-terminal ECD & $\checkmark$ \\
\hline $\mathrm{S} 130$ & 84 & & N-terminal ECD & \\
\hline L134 & 93 & & N-terminal ECD & \\
\hline R145 & 84 & & N-terminal ECD & \\
\hline R174 & 83 & 1.63 & TM1 & \\
\hline C178 & 100 & 2.44 & TM2 & \\
\hline $\mathrm{R} 180$ & 100 & 2.46 & TM2 & \\
\hline $\mathrm{I} 183$ & 83 & 2.49 & TM2 & \\
\hline N181 & 93 & 2.47 & TM2 & \\
\hline H184 & 100 & 2.50 & TM2 & $\checkmark$ \\
\hline L187 & 86 & 2.53 & TM2 & \\
\hline L193 & 93 & 2.59 & TM2 & \\
\hline C217 & 93 & 3.29 & TM3 & \\
\hline Y226 & 80 & 3.38 & TM3 & \\
\hline N231 & 93 & 3.43 & TM3 & \\
\hline W234 & 93 & 3.46 & TM3 & \\
\hline E238 & 86 & 3.50 & TM3 & \\
\hline Y241 & 86 & 3.53 & TM3 & \\
\hline L242 & 86 & 3.54 & TM3 & \\
\hline G264 & 93 & 4.49 & TM4 & $\checkmark$ \\
\hline W265 & 93 & 4.50 & TM4 & \\
\hline G266 & 79 & 4.51 & TM4 & \\
\hline P268 & 93 & 4.53 & TM4 & \\
\hline W275 & 86 & 4.60 & TM4 & \\
\hline C287 & 93 & & ECL2 & \\
\hline W288 & 93 & & ECL2 & $\checkmark$ \\
\hline $\mathrm{I} 300$ & 86 & 5.38 & TM5 & \\
\hline P304 & 86 & 5.42 & TM5 & \\
\hline N312 & 86 & 5.50 & TM5 & \\
\hline F313 & 86 & 5.51 & TM5 & \\
\hline L323 & 93 & 5.61 & TM5 & \\
\hline K326 & 93 & 5.64 & TM5 & \\
\hline L327 & 93 & 5.65 & TM5 & \\
\hline K343 & 86 & 6.40 & TM6 & \\
\hline T345 & 93 & 6.42 & TM6 & \\
\hline
\end{tabular}




\begin{tabular}{|c|c|c|c|c|}
\hline L346 & 86 & 6.43 & TM6 & \\
\hline L348 & 93 & 6.45 & TM6 & \\
\hline P350 & 86 & 6.47 & TM6 & \\
\hline L351 & 86 & 6.48 & TM6 & \\
\hline L352 & 93 & 6.49 & TM6 & \\
\hline G353 & 100 & 6.50 & TM6 & \\
\hline F359 & 100 & 6.56 & TM6 & \\
\hline S382 & 93 & 7.47 & TM7 & \\
\hline F383 & 100 & 7.48 & TM7 & $\checkmark$ \\
\hline Q384 & 93 & 7.49 & TM7 & $\checkmark$ \\
\hline G385 & 100 & 7.50 & TM7 & $\checkmark$ \\
\hline V388 & 100 & 7.53 & TM7 & \\
\hline Y392 & 93 & 7.57 & TM7 & \\
\hline C393 & 93 & 7.59 & TM7 & \\
\hline F394 & 93 & & TM7 & \\
\hline N396 & 100 & & H8 & \\
\hline E398 & 100 & & H8 & \\
\hline V399 & 100 & &
\end{tabular}


Table S5. Residue distance for molecular switches (1-2), gate residue distance between TM6 and TM7

(3), and for remote residues in antagonist binding site (4-6) examined in the literature. Potential

interhelical salt bridges (7-17) and side chain-side chain H-bonds (18-21) examined in this study.

Conserved residues in both class B and subfamily B 1 GPCRs (blue); conserved residues in subfamily B 1

only (green).

\begin{tabular}{|c|c|c|}
\hline $\mathbf{S} / \mathbf{N}$ & Residues Distance & Description \\
\hline 1 & $\mathrm{R} 180^{2.46}: \mathrm{E} 238^{3.50}$ & Ionic lock between TM2 and TM3 $[6,26]$ \\
\hline 2 & $\mathrm{H} 184^{2.50}: \mathrm{E} 238^{3.50}$ & Polar lock between TM2 and TM3 $[6,26]$ \\
\hline 3 & $\mathrm{~S} 333^{6.30}: \mathrm{L} 395^{7.60}$ & Gate residues at TM6 and TM7 \\
\hline 4 & $\mathrm{~F} 232^{3.44}: \mathrm{Y} 356^{6.53}$ & Remote residues in antagonist binding site [6] \\
\hline 5 & $\mathrm{H} 228^{3.40}: \mathrm{Y} 356^{6.53}$ & Remote residues in antagonist binding site [6] \\
\hline 6 & $\mathrm{~N} 312^{5.50}: \mathrm{Y}_{356^{6.53}}$ & Remote residues in antagonist binding site [6] \\
\hline 7 & $\mathrm{R} 180^{2.46}: \mathrm{E} 398^{\mathrm{H} 8}$ & Salt bridge between TM1 and H8 \\
\hline 8 & $\mathrm{D} 156^{\mathrm{TM} 1}: \mathrm{R} 194^{2.60}$ & Salt bridge between TM1 and TM2 \\
\hline 9 & $\mathrm{D} 283^{4.68}: \mathrm{R} 292^{\mathrm{ECL} 2}$ & Salt bridge between TM4 and ECL2 \\
\hline 10 & $\mathrm{E}^{285^{\mathrm{ECL} 2}}: \mathrm{R} 292^{\mathrm{ECL} 2}$ & Salt bridge between distant residues within ECL2 \\
\hline 11 & $\mathrm{~K} 291^{\mathrm{ECL} 2}: \mathrm{D} 298^{5.36}$ & Salt bridge between ECL2 and TM5 \\
\hline 12 & D366 ${ }^{\mathrm{ECL} 3}: \mathrm{R} 370^{7.35}$ & Salt bridge between ECL3 and TM7 \\
\hline 13 & $\mathrm{E} 208^{\mathrm{ECL} 1}: \mathrm{K} 286^{\mathrm{ECL} 2}$ & Salt bridge between ECL1 and ECL2 \\
\hline 14 & $\mathrm{R} 218^{3.30}: \mathrm{E} 285^{\mathrm{ECL} 2}$ & Salt bridge between TM3 and ECL2 \\
\hline 15 & $\mathrm{R} 173^{\mathrm{ICL} 1}: \mathrm{E} 398^{\mathrm{H} 8}$ & Salt bridge between ICL1 and H8 \\
\hline 16 & $\mathrm{~K} 291^{\mathrm{ECL} 2}: \mathrm{E} 367^{7.32}$ & Salt bridge between ECL2 and TM7 \\
\hline 17 & $\mathrm{R} 194^{2.60}: \mathrm{E} 381^{7.46}$ & Salt bridge between TM2 and TM7 \\
\hline 18 & $\mathrm{D} 156^{\mathrm{TM} 1}: \mathrm{Q} 202^{2.68}$ & H-bond between TM1 and TM2 \\
\hline 19 & $\mathrm{E} 160^{\mathrm{TM} 1}: \mathrm{N} 195^{2.61}$ & H-bond between TM1 and TM2 \\
\hline 20 & $\mathrm{Y} 356^{6.53}: \mathrm{Q} 384^{7.49}$ & H-bond between TM6 and TM7 \\
\hline 21 & $\mathrm{~N} 362^{\mathrm{ECL} 3}: \mathrm{R} 370^{7.35}$ & H-bond between ECL3 and TM7 \\
\hline
\end{tabular}

Note: Distances 1 and 7-17 are measured between O and N. Distances 3-6 were measured between the center of mass of the residue pairs. Distances 18 to 21 are measured between $\mathrm{NH}$ and $\mathrm{O}$ and between $\mathrm{OH}$ and $\mathrm{N}$. N312 $3.5086 \%$ conserved in class B and subfamily B 1 of class B GPCRs. R180 $2.46, \mathrm{H} 184^{2.50}$, E238 ${ }^{3.50}$ and Q384 ${ }^{7.49}$ are $83 \%$ conserved in class B and subfamily B 1 GPCRs. R1942.60, Y356 $6^{6.53}$, and E398 ${ }^{\mathrm{H} 8}$ are $66 \%, 72 \%$, and 83\% conserved, respectively, in Subfamily B 1 GPCRs. The rest of the residues are neither conserved in class B nor in subfamily B 1 GPCRs. Distances 3-6 were measured between the center of mass of the residue pairs. 


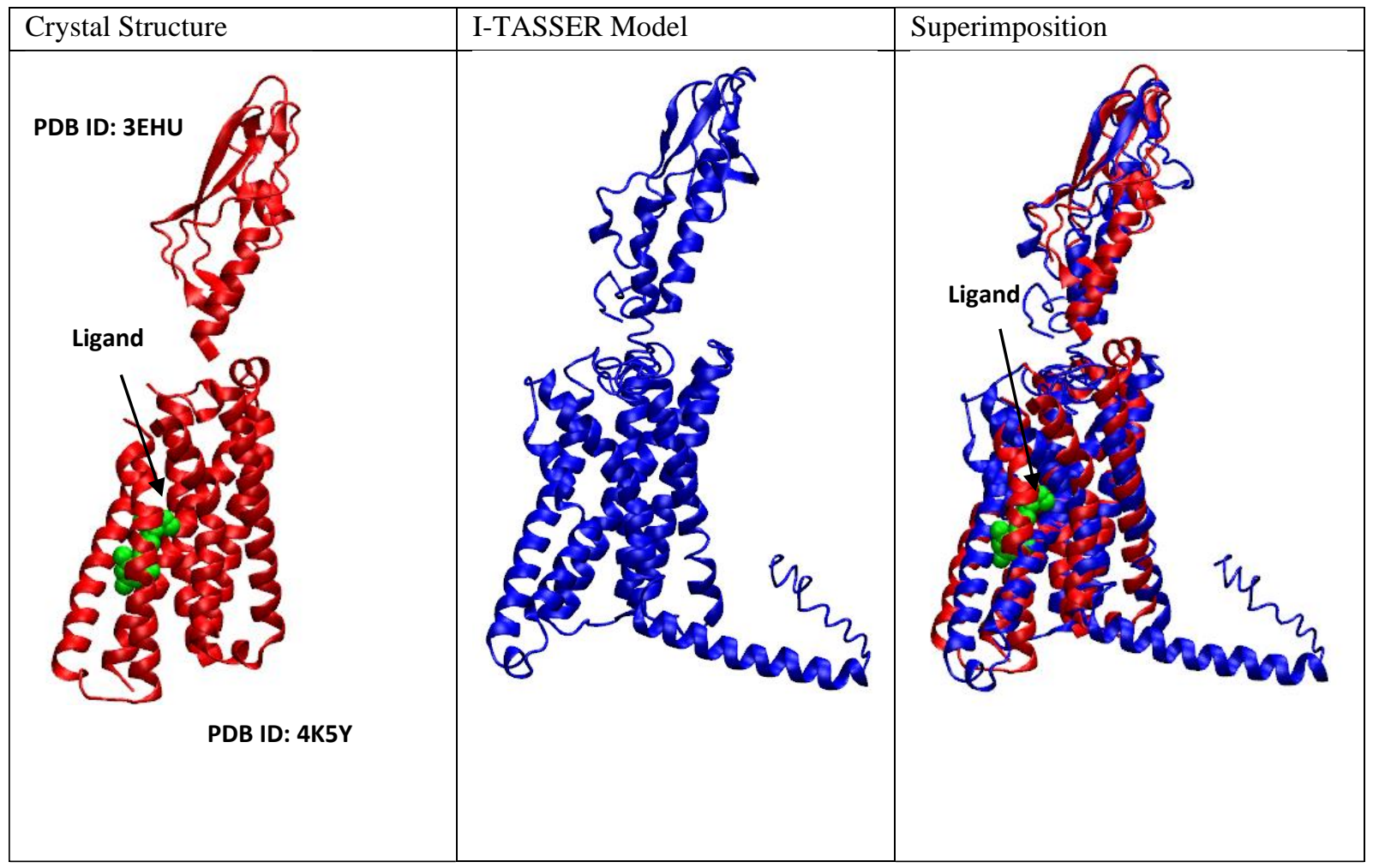

Figure S1. Comparison between our homology model and the two crystal structures (PDB IDs: 3EHU and 4K5Y). 3EHU: Extracellular domain only; 4K5Y: Transmembrane domain only with an antagonist ligand, CP-376395. 
A

Frames Aligned Based on Transmembrane Helices 1-7

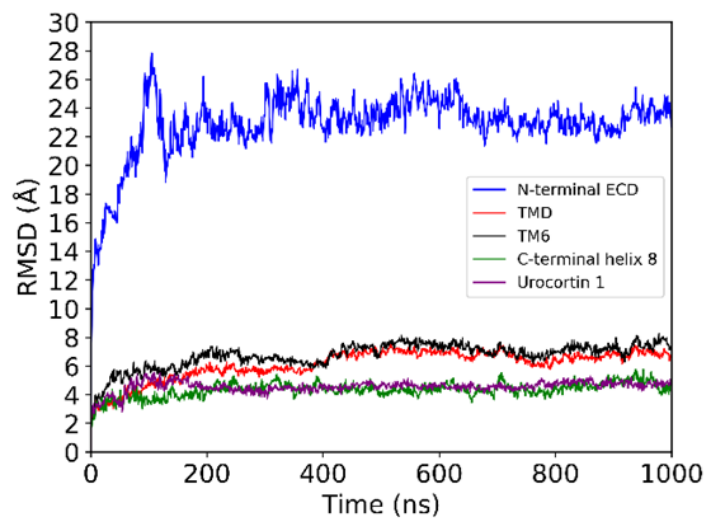

B

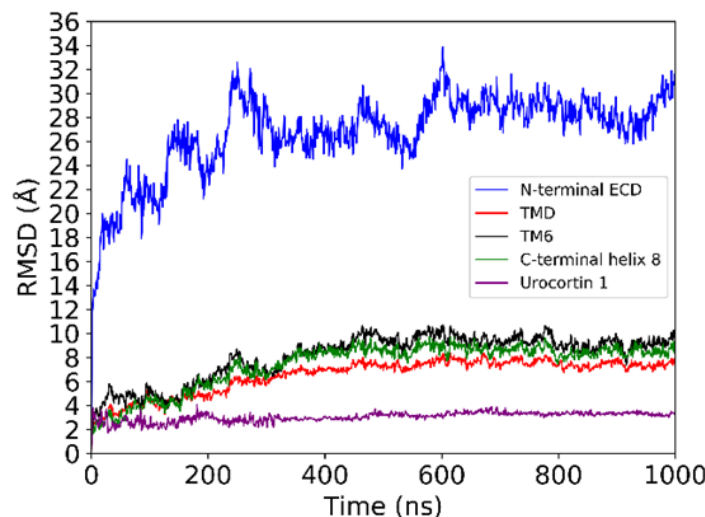

C

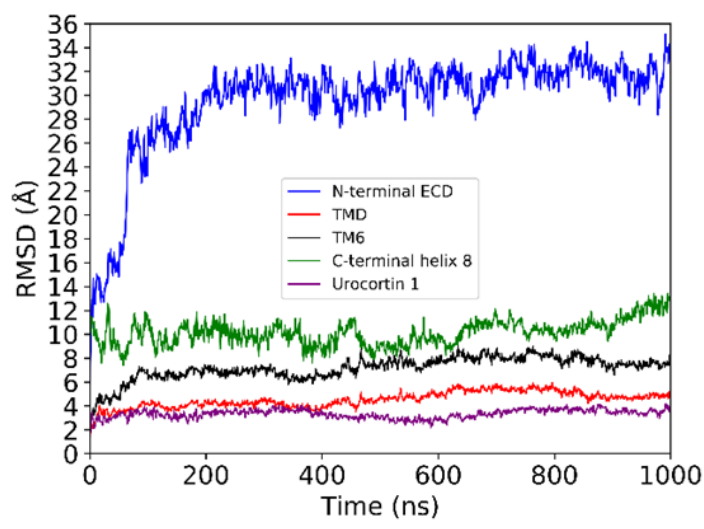

Frames Aligned Based on Transmembrane Helices 1-5 and 7
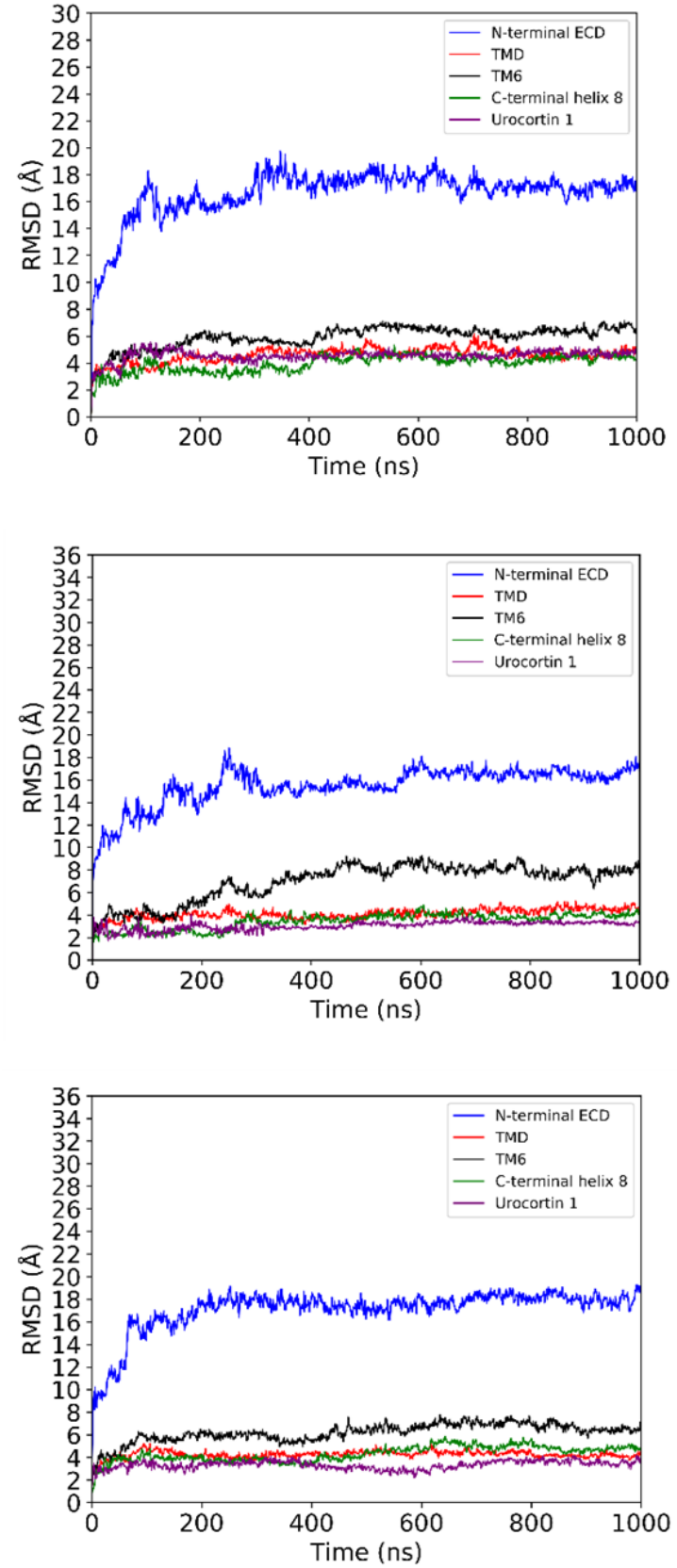

Figure S2. RMSD profiles of the 3 trajectories of the agonist urocortin 1 bound CRF1R. All frames were aligned based on the TMD with TM6 (left) and without TM6 (right): (A) first trajectory; (B) second trajectory; (C) third trajectory. 
Frames Aligned Based on Transmembrane Helices 1-7

Frames Aligned Based on Transmembrane Helices 1-5 and 7

A
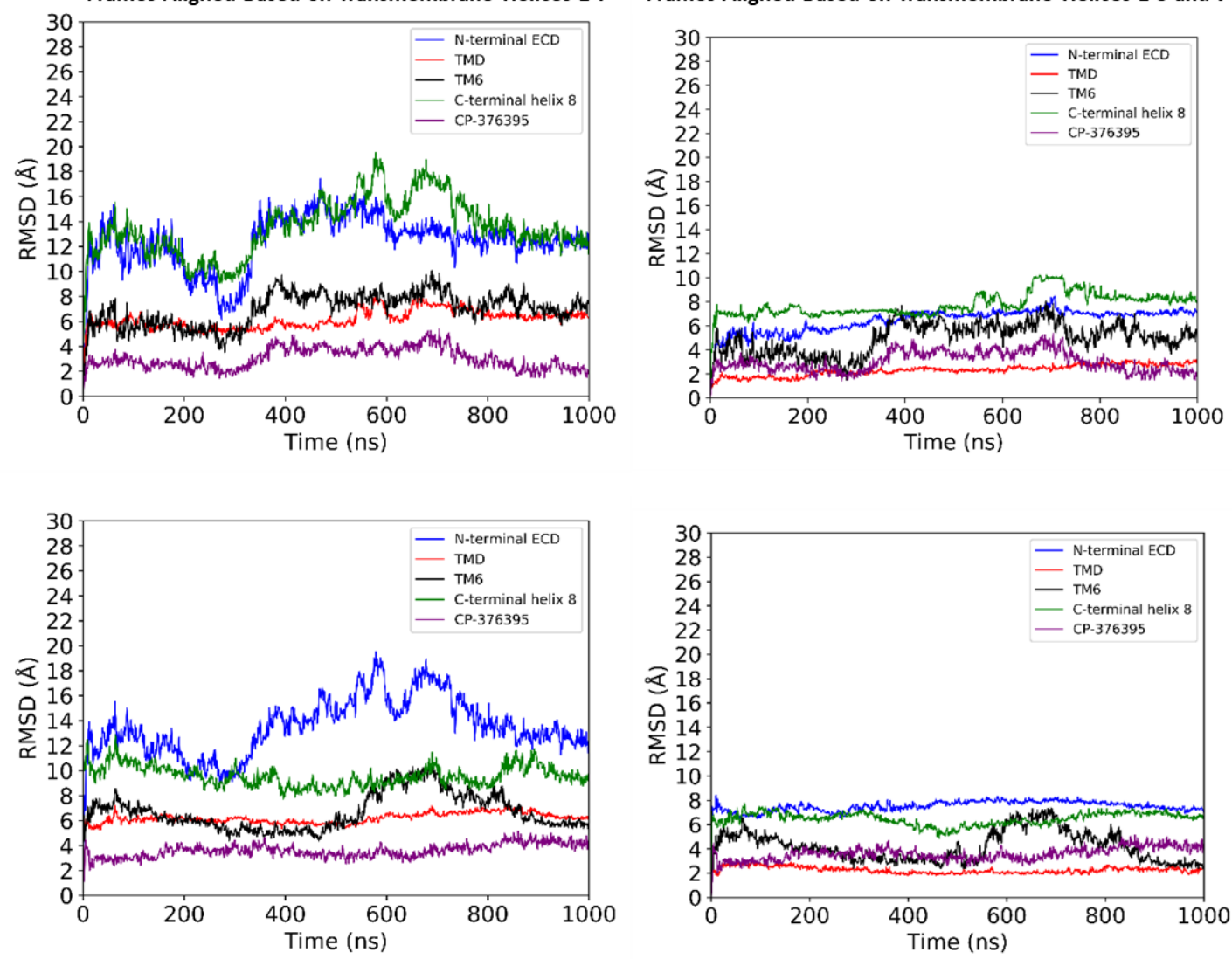

C
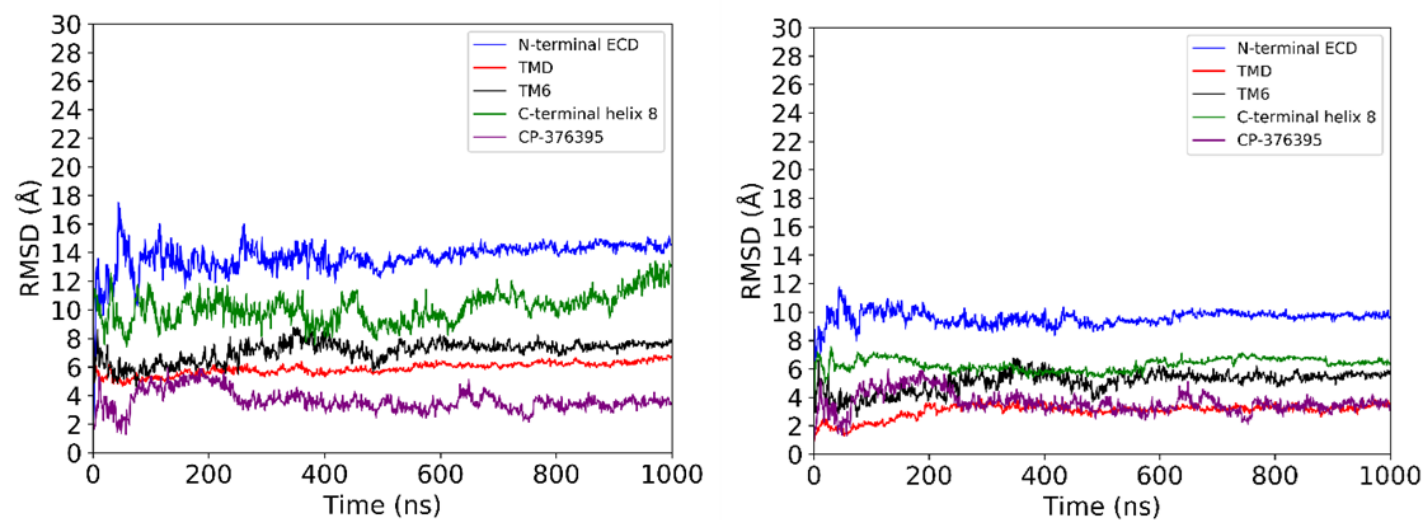

Figure S3. RMSD profiles of the 3 trajectories of the antagonist CP-376395-bound CRF1R. All frames were aligned based on the TMD with TM6 (Left) and without TM6 (Right): (A) first trajectory. (B) second trajectory. (C) third trajectory. 
A Frames Aligned Based on Transmembrane Helices 1-7

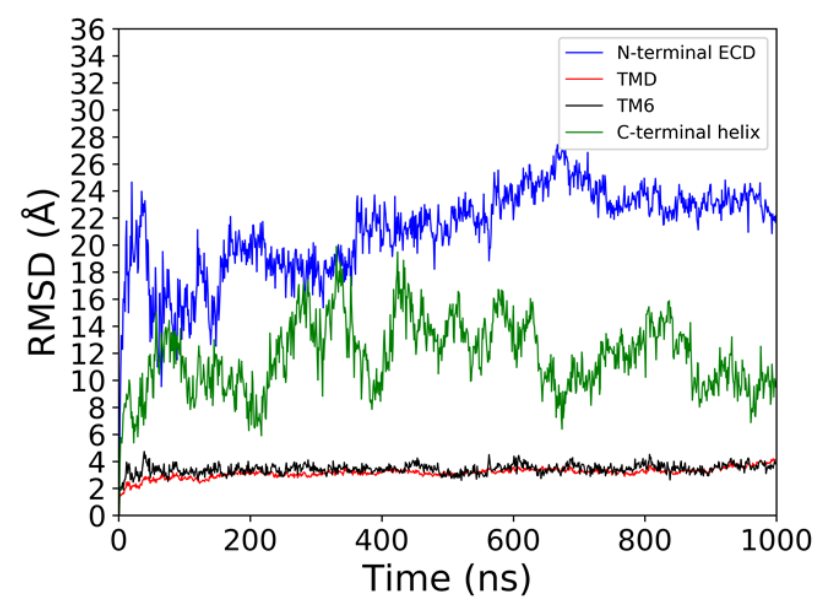

B Frames Aligned Based on Transmembrane Helices 1-5 and 7

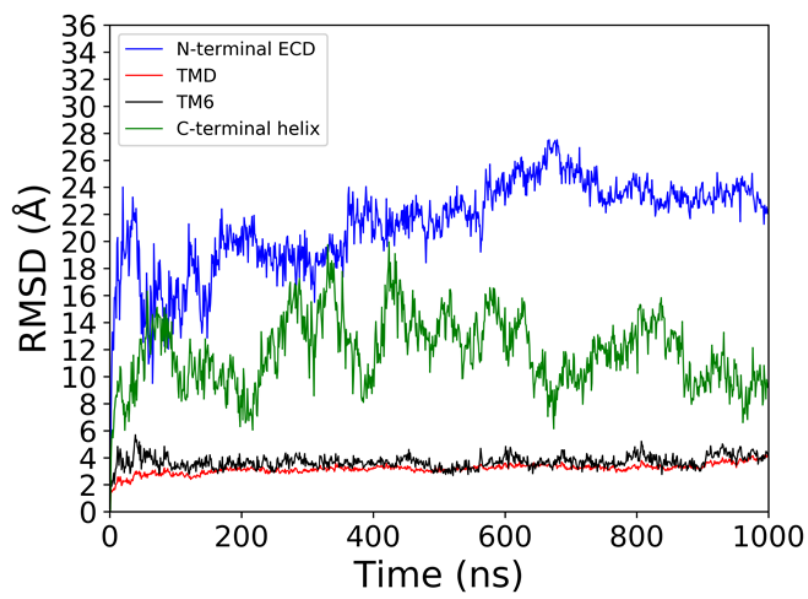

Figure S4. Average C $\alpha$ Root Mean-Square Deviation (RMSD) profiles of apo CRF1R. All frames were aligned based on the TMD (A) with TM6, and (B) without TM6. 

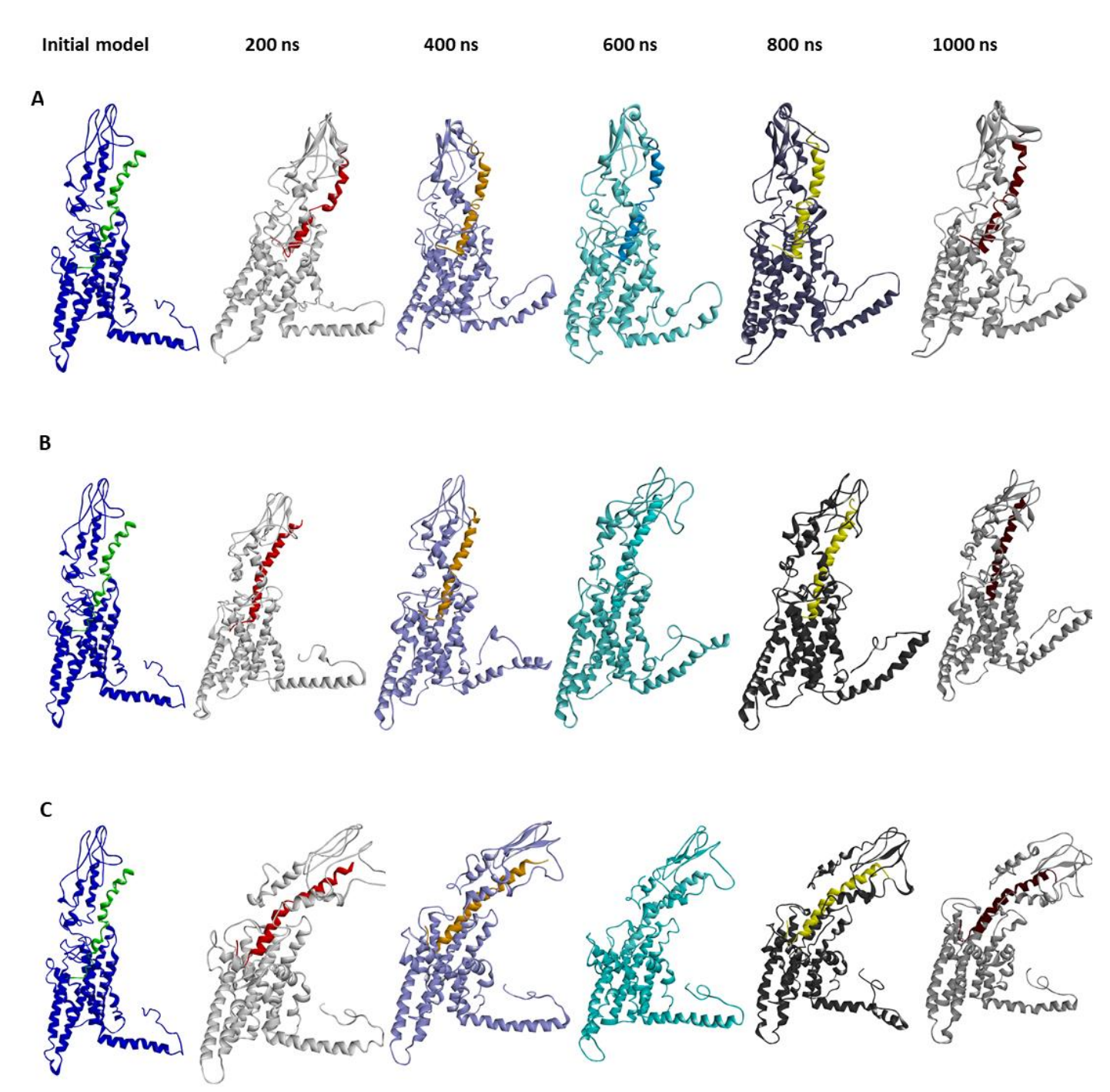

Figure S5. Evolution of the agonist urocortin 1 bound CRF1R systems: (A) first trajectory; (B) second trajectory; (C) third trajectory. 

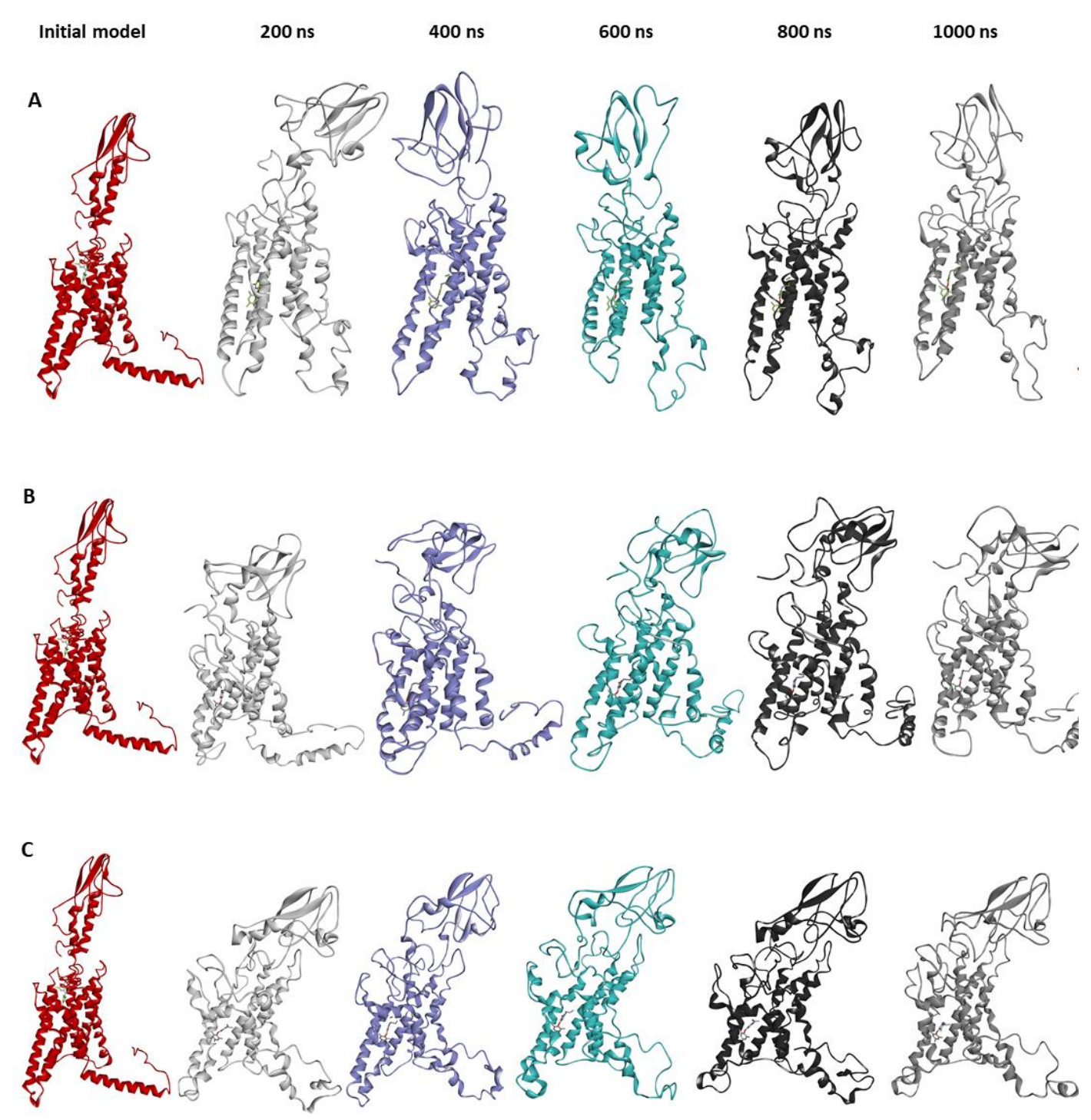

Figure S6. Evolution of the antagonist CP-376395-bound CRF1R: (A) first trajectory; (B) second trajectory; (C) third trajectory. 


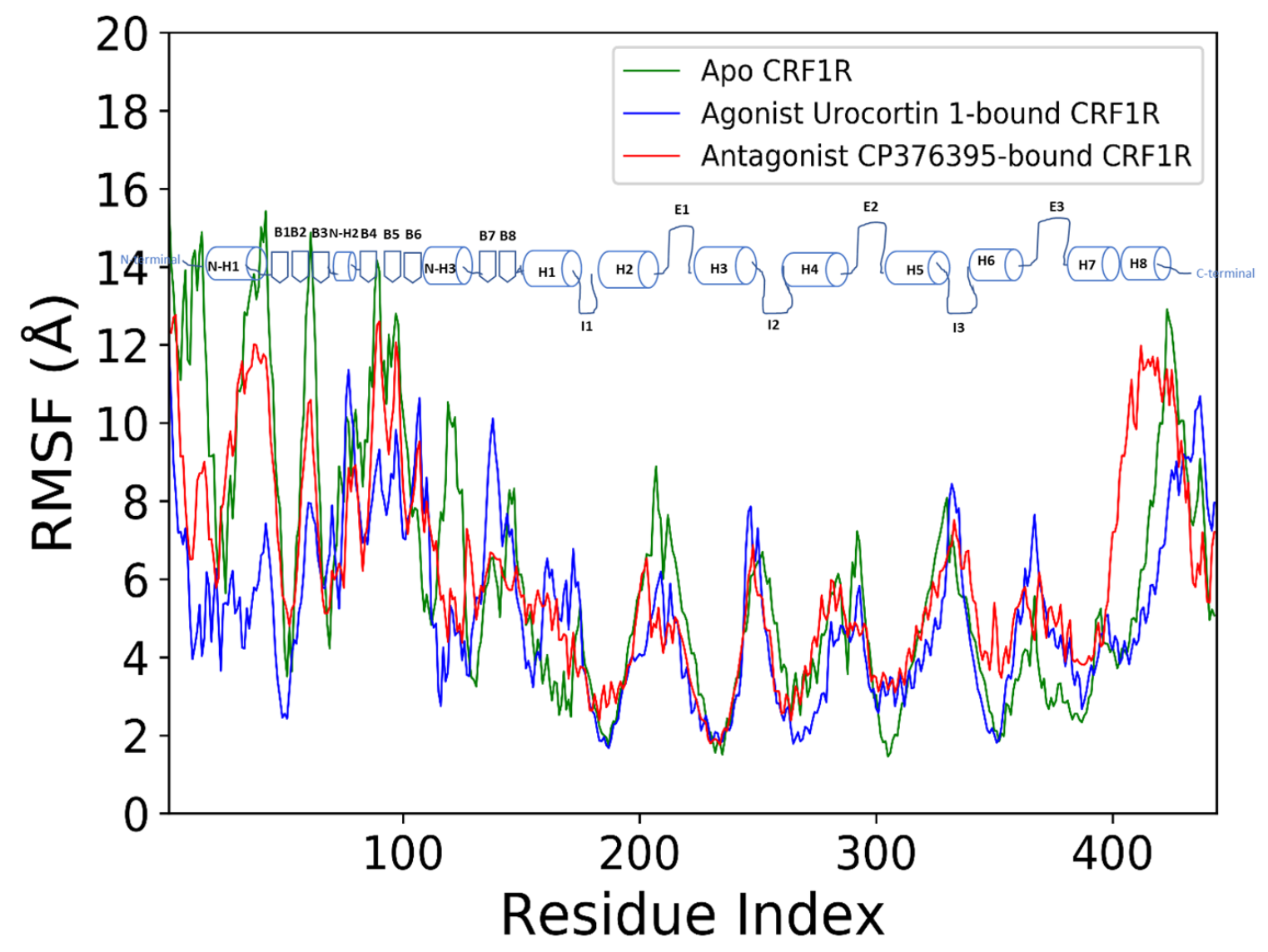

Figure S7. Average C $\alpha$ root mean-square fluctuation (RMSF) profiles of apo CRF1R and of the agonist urocortin 1 bound CRF1R (Blue) and antagonist CP-376395-bound CRF1R (Red) (over 3 trajectories). $\mathrm{N}$-terminal ECD and $\mathrm{C}$-terminal regions show larger fluctuations than the TMD regions. 

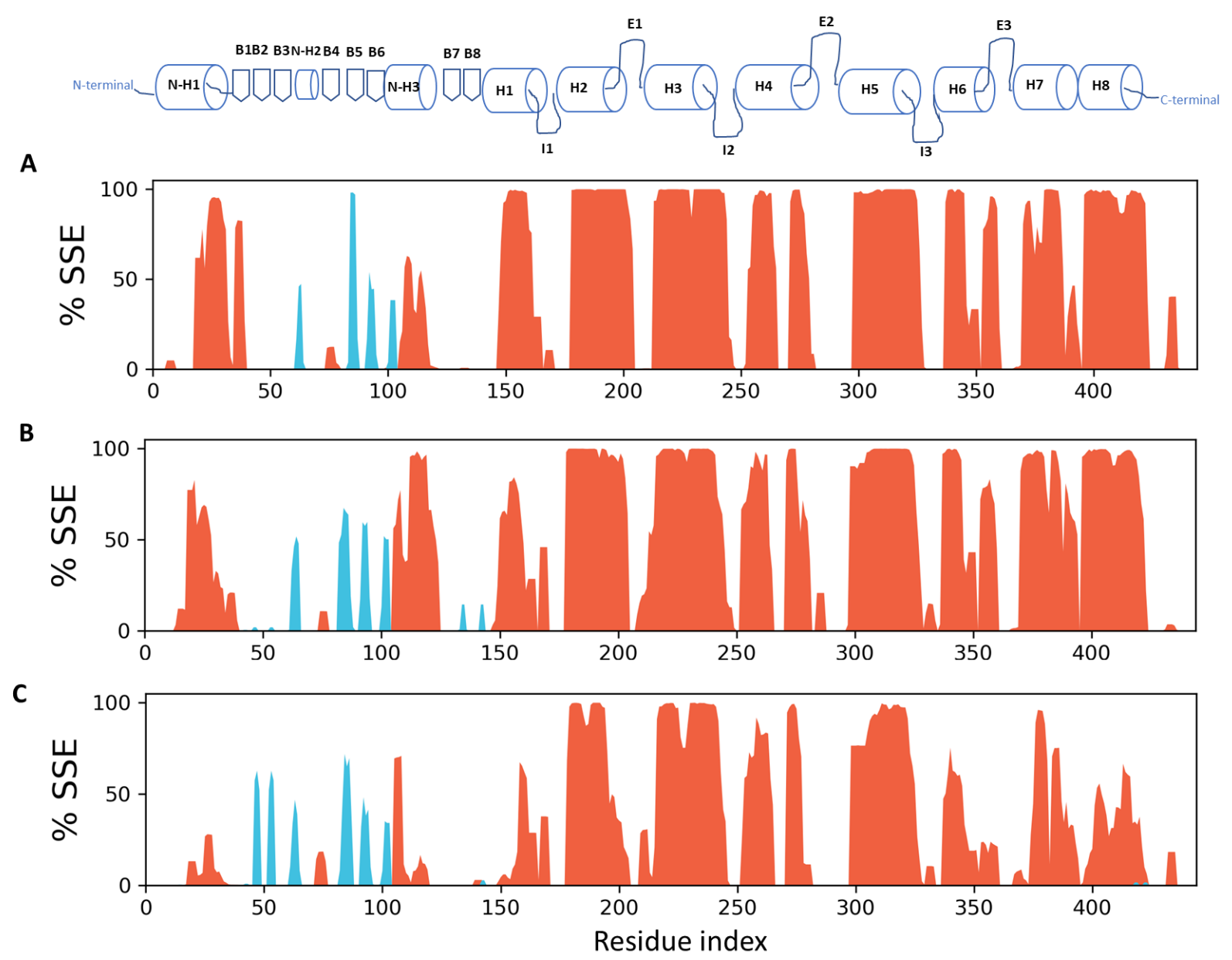

Figure S8. Secondary structure elements: (A) apo CRF1R; (B) agonist bound CRF1R; (C) antagonist bound CRF1R. The average percentage of the helical content is about $54 \%$ for a trajectory of apo CRF1R, and 52\% and 38\% over 3 trajectories of the agonist-bound system and antagonist-bound system, respectively. Orange represents alpha helices; blue represents beta sheets. N-terminal region: residues 1-145, TM1: 146-170, TM2: 178-205, TM3: 215-248, TM4: 255-281, TM5: 298-330, TM6: 333-361, TM7: 370-395, C-terminal region: 396-444. 

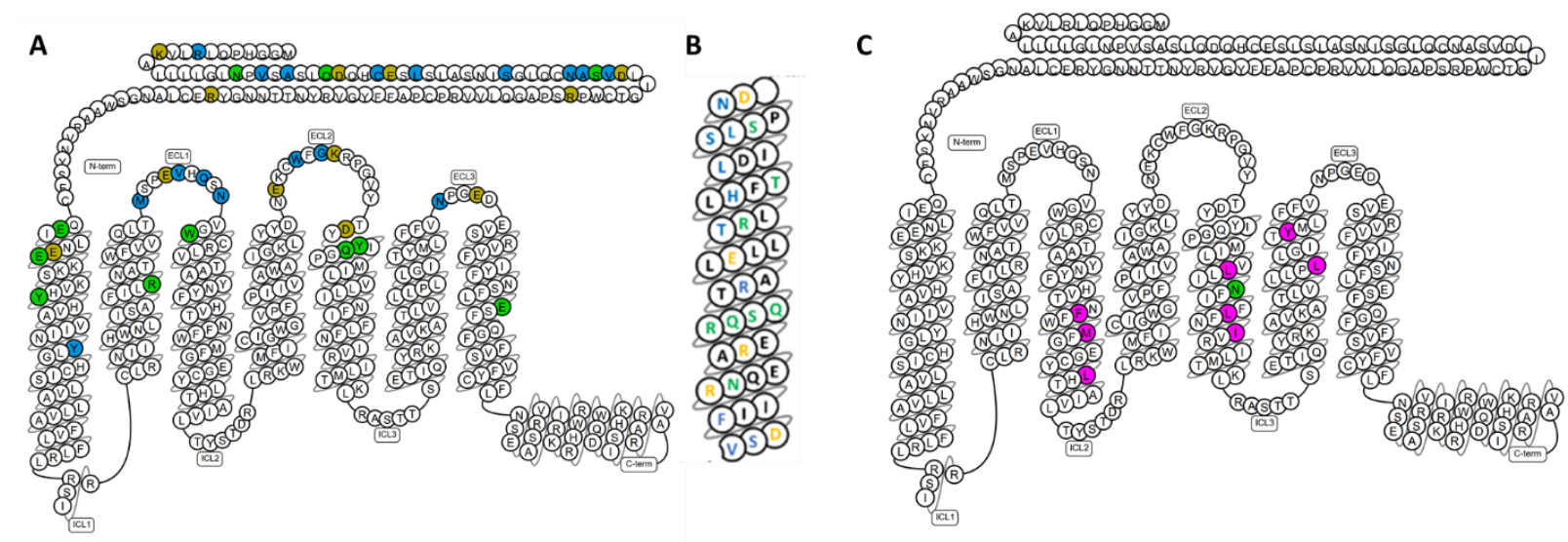

Figure S8. Interactions between CRF1R and ligands. (A) Snake plot representation of CRF1R showing location of the residues that interact with the peptide agonist urocortin 1 (occupancy: $>10 \%$ ). (B) The corresponding residues of the peptide agonist urocortin 1 that interact with the CRF1R. (C) Residues in CRF1R that interact with the small molecule antagonist CP-356395 (occupancy: 5\% and above). The interactions are color coded: H-bond_ss (side chains-side) (green), H-bond_sb (side chain-backbone) (blue), and H-bond_bs (backbone-side chain) (gray), salt bridge (yellow), and hydrophobic interaction (pink). 
(A)

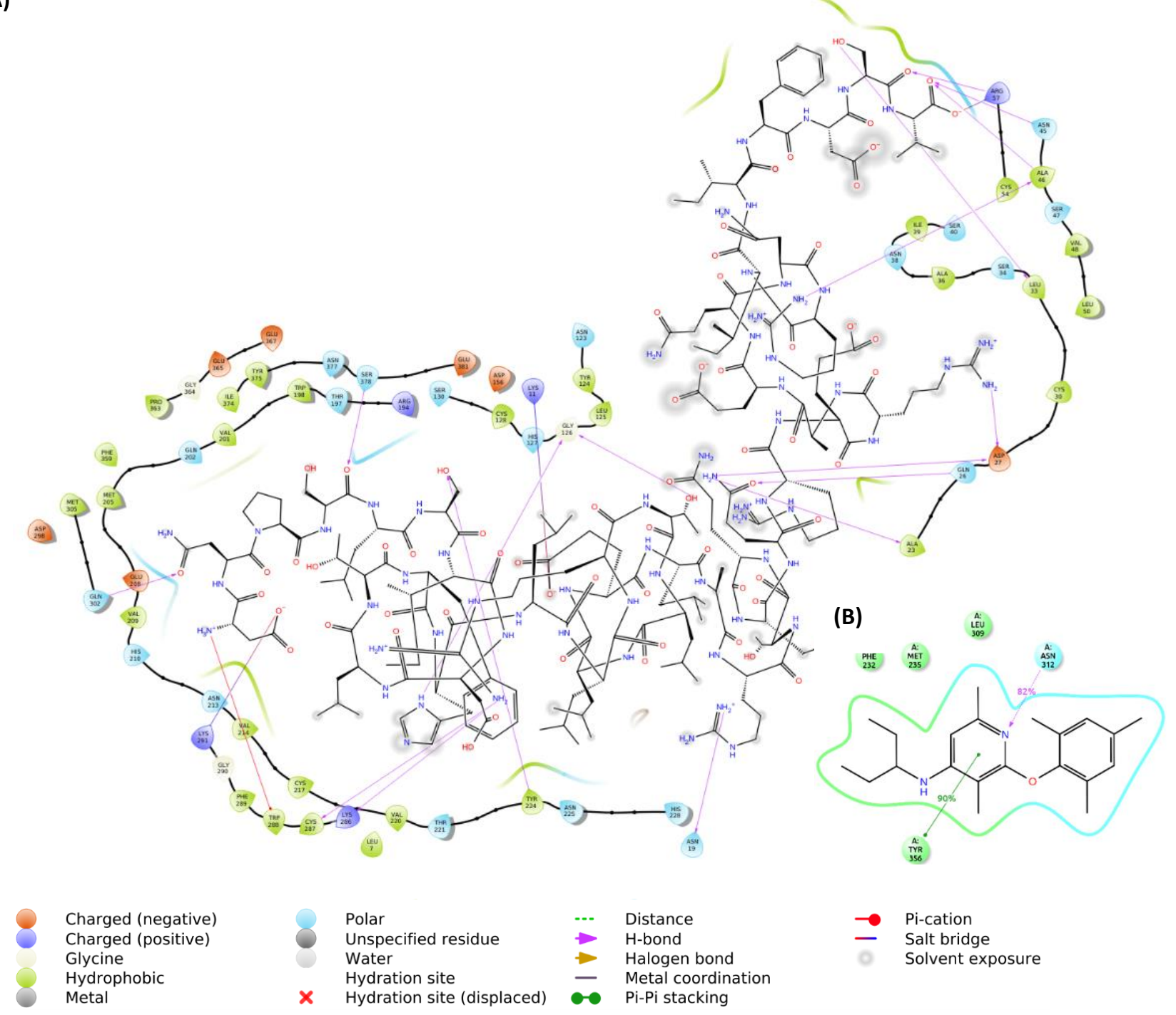

Figure S9. Interaction between CRF1R and peptide agonist urocortin 1 in the representative structure of the most abundant cluster (A). Interaction between CRF1R and the small antagonist CP 376395 (B). 


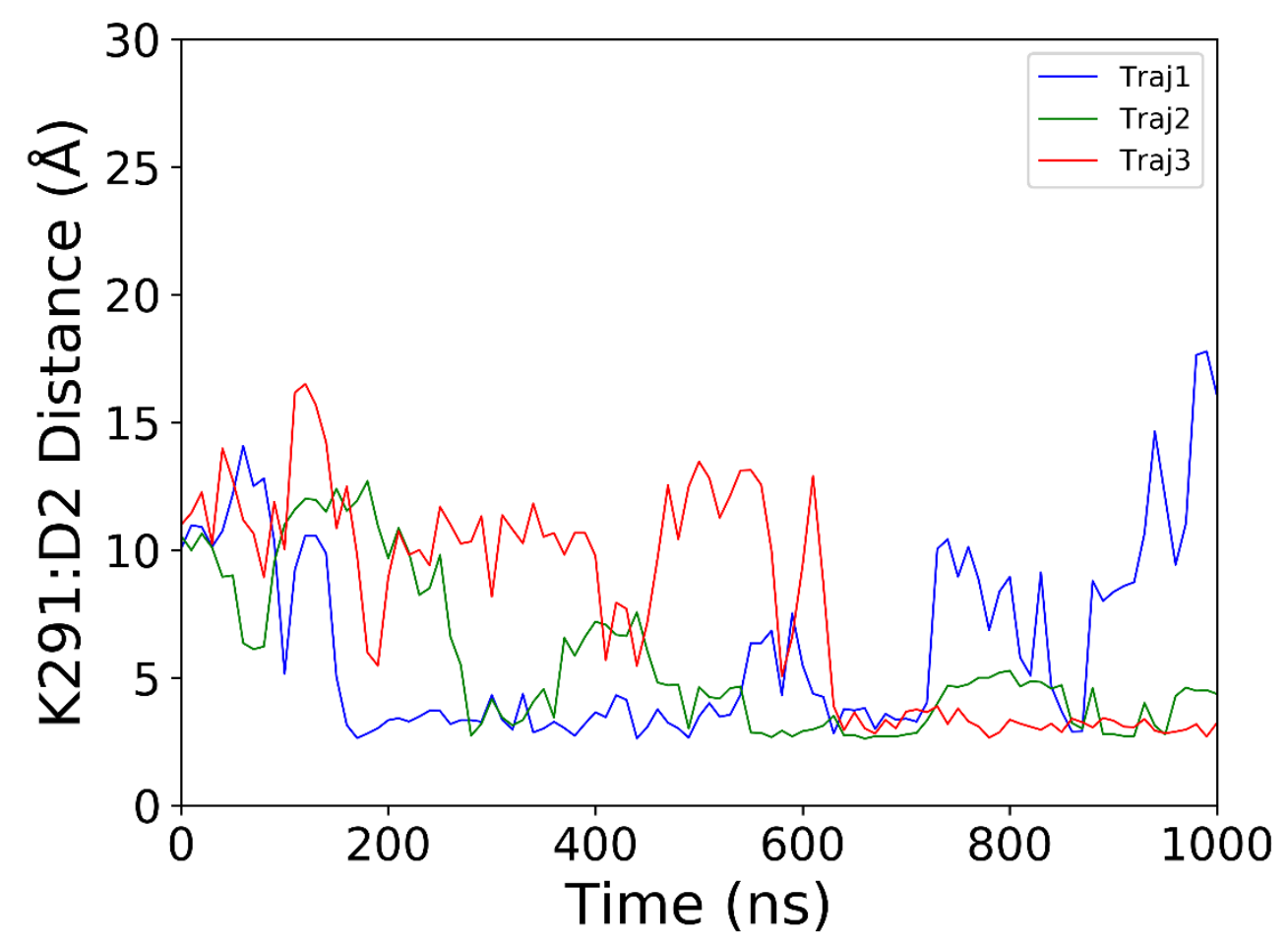

Figure S10. Most persistent interaction in the peptide agonist urocortin 1 bound system (between $\mathrm{K} 291^{\mathrm{ECL} 2}$ and D2 in the peptide agonist). 

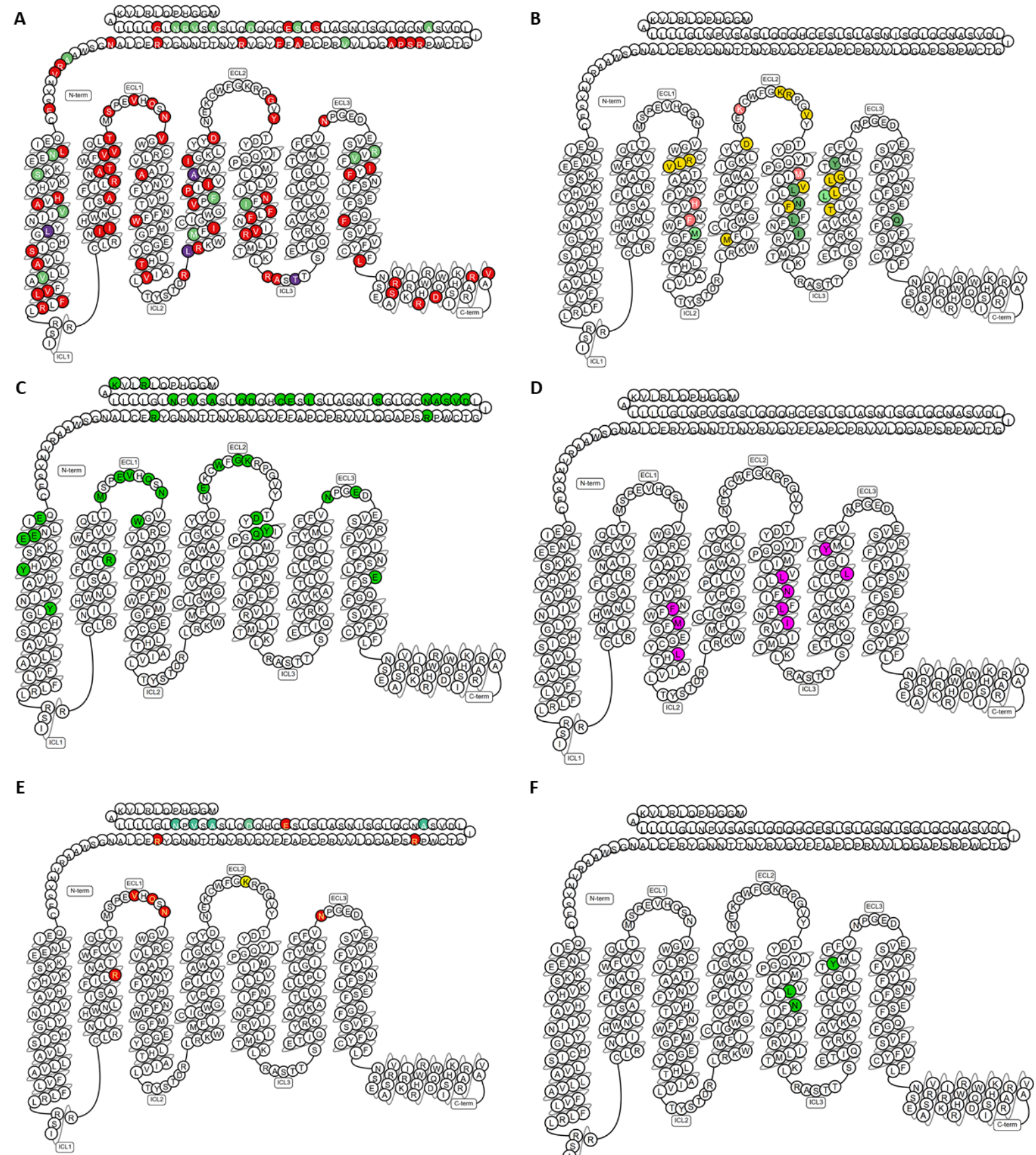

F

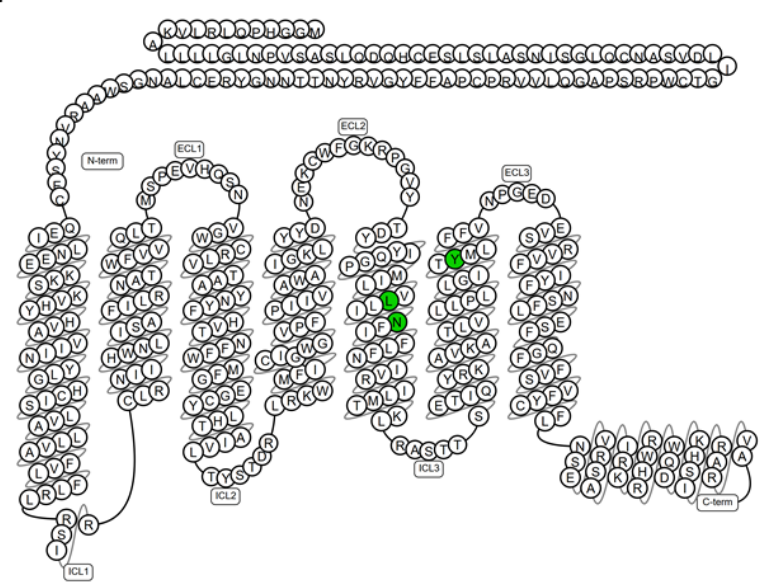

Figure S11. Cross-referencing key interacting residues (occupancy: 10\% and above) with mutagenesis data: (A) natural genetic variation (deleterious; deleterious; tolerated); (B) in vitro mutation (increased binding/potency: $>5$ fold, >10-fold; reduced binding/potency: $>5$-fold, $>10$-fold; no/low effect ( $<5$-fold); and N/A); (C) key interacting residue in the agonist urocortin 1-bound CRF1R; (D) key interacting residue in the antagonist CP-376395 bound CRF1R; (E) key interacting residue in the agonist urocortin 1 bound CRF1R that overlap with the mutagenesis data; (F) key interacting residue in the antagonist CP-376395-bound CRF1R that overlap with the mutagenesis data. 

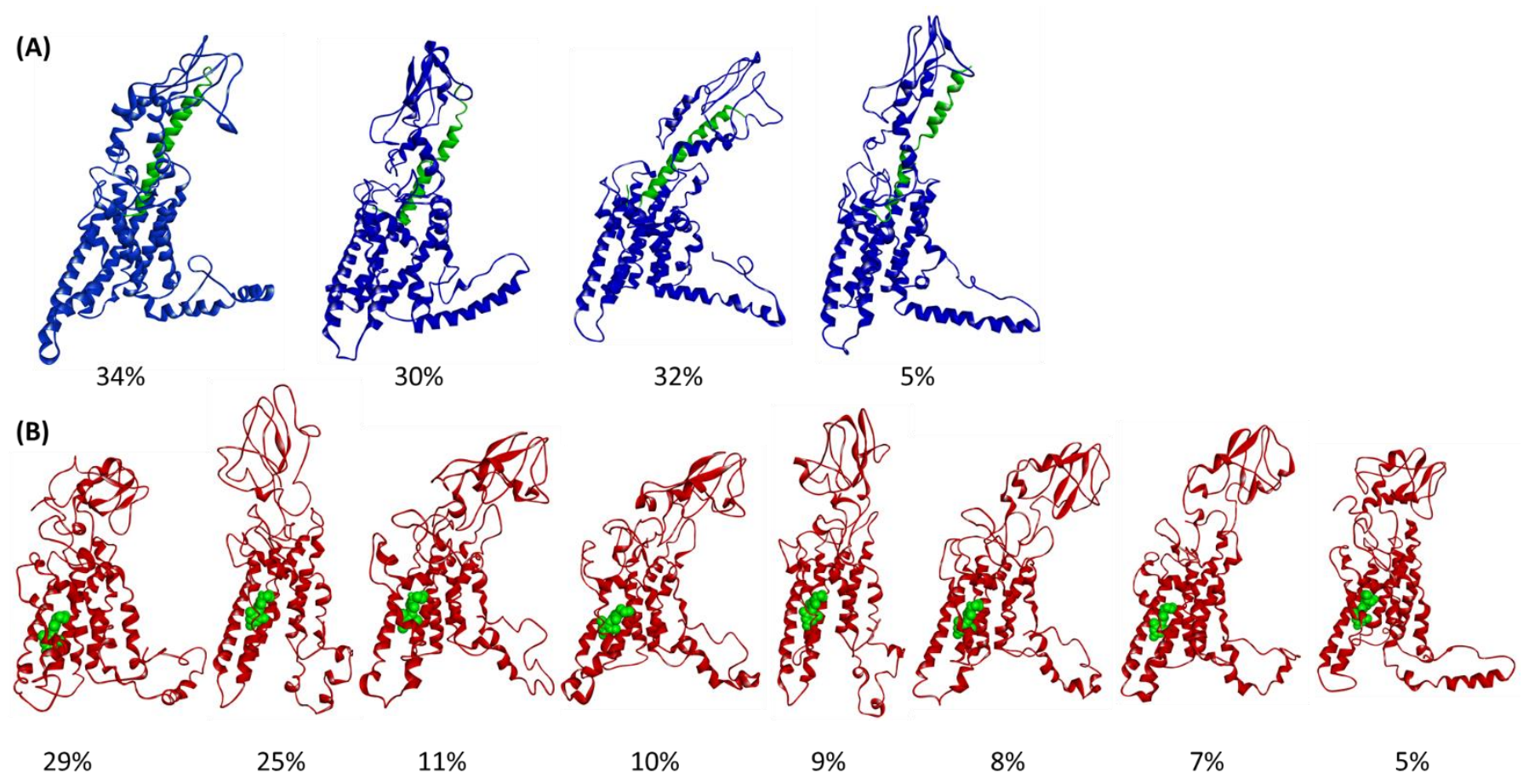

Figure S12. Representative structures of clusters ranked from most abundant to least abundant (left to right): (A) peptide agonist urocortin 1 bound CRF1R; (B) small molecule antagonist CP376395-bound CRF1R. 


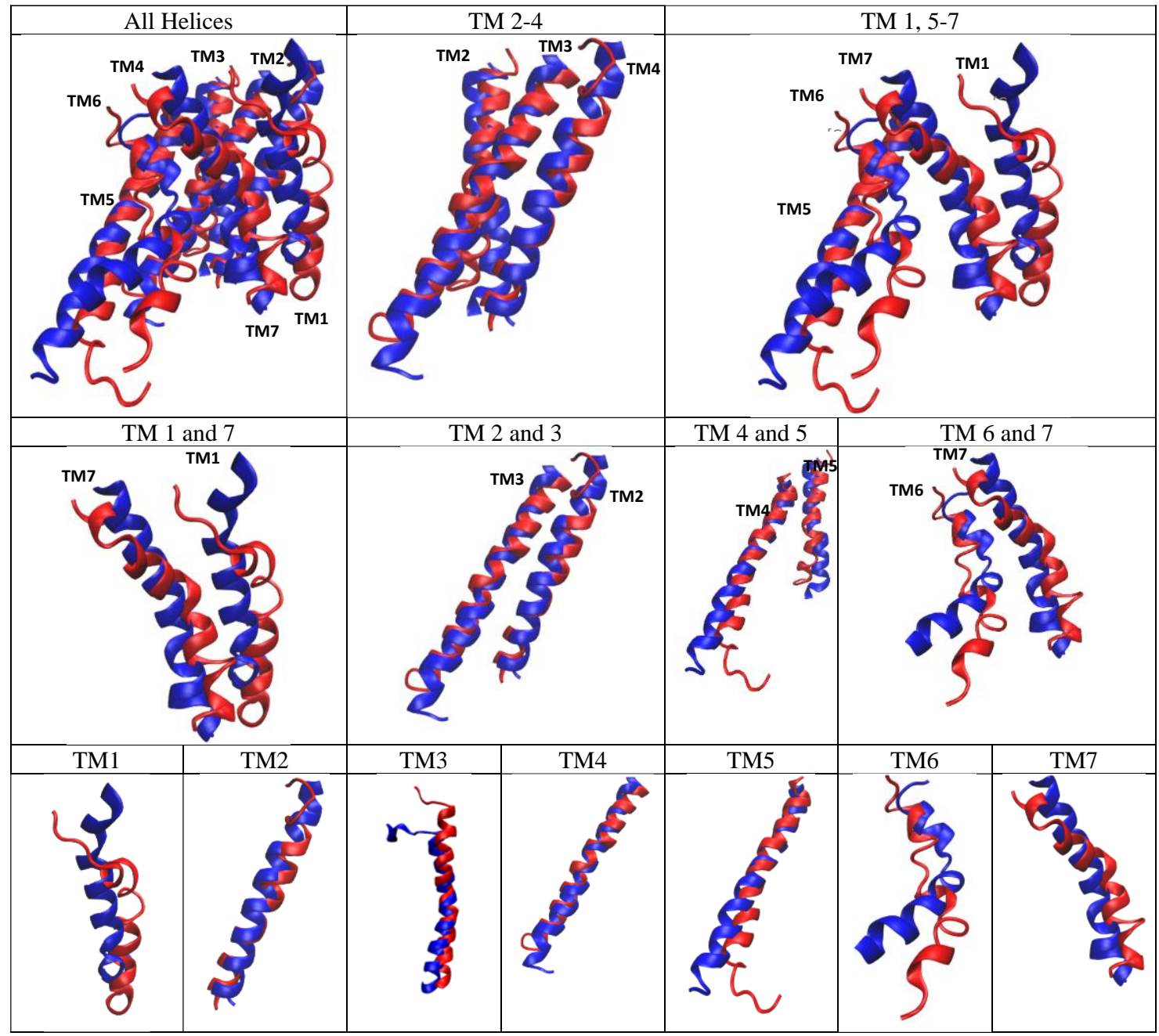

Figure S13. Detailed structure comparison for the transmembrane region. Blue color: agonist urocortin 1 bound CRF1R; red color: antagonist CP-376395 bound CRF1R. TM1, 5-7 show high deviation in the agonist urocortin 1 bound CRF1R, whereas TM2, 3 and 4 retain their position in both systems. 


\begin{tabular}{|c|c|c|c|}
\hline Index No. & Distance $(\AA)$ & Agonist urocortin 1 bound CRF1R & Antagonist CP-376395 bound CRF1R \\
\hline 1 & $\begin{array}{c}\mathrm{R} 180^{2.46}: \mathrm{E} 238^{3.50} \\
(\mathrm{~N}---\mathrm{O})\end{array}$ & 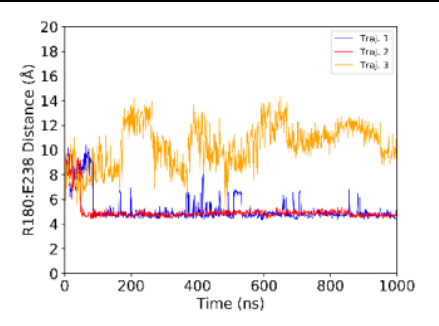 & 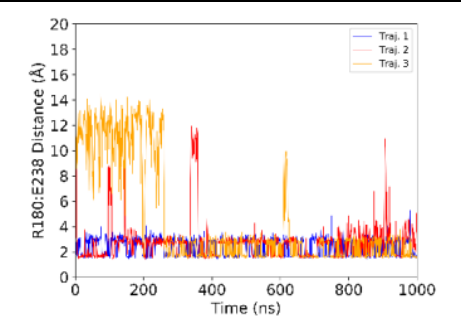 \\
\hline 2 & $\begin{array}{c}\mathrm{H} 184^{2.50}: \mathrm{E} 238^{3.50} \\
(\mathrm{~N}---\mathrm{O})\end{array}$ & 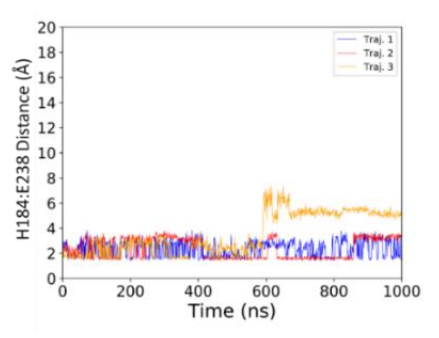 & 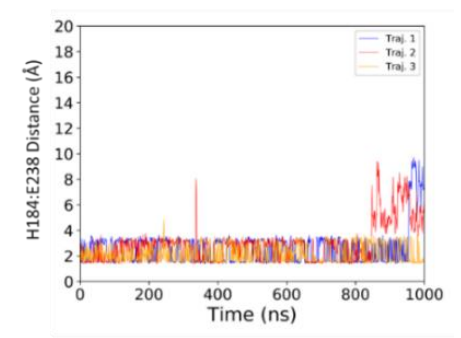 \\
\hline 3 & $\begin{array}{l}\mathrm{S} 333^{6.30}: \mathrm{L} 395^{7.60} \\
\text { (Center of Mass) }\end{array}$ & 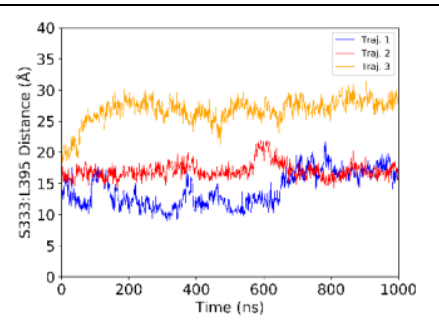 & 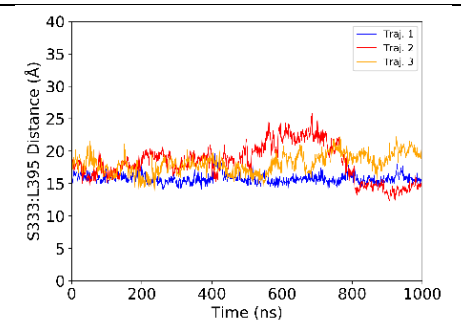 \\
\hline 4 & $\begin{array}{l}\text { F232 } 32^{3.44}: Y 356^{6.53} \\
\text { (Center of Mass) }\end{array}$ & 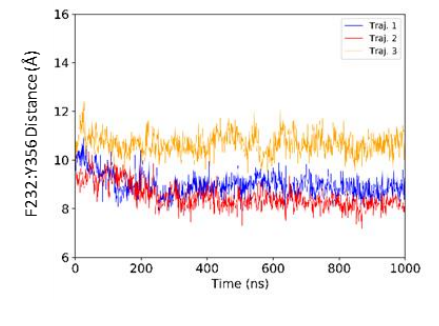 & 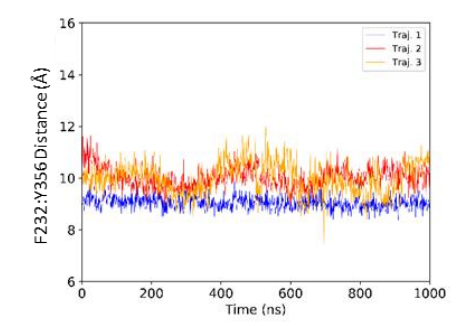 \\
\hline 5 & $\begin{array}{l}\mathrm{H} 228^{3.40}: Y_{356^{6.53}} \\
\text { (Center of Mass) }\end{array}$ & 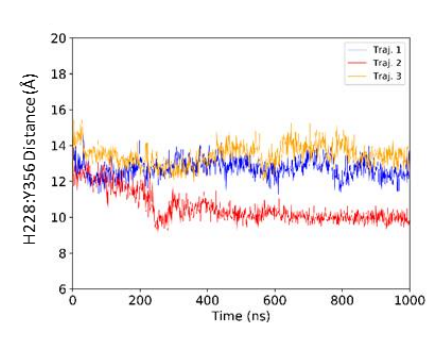 & 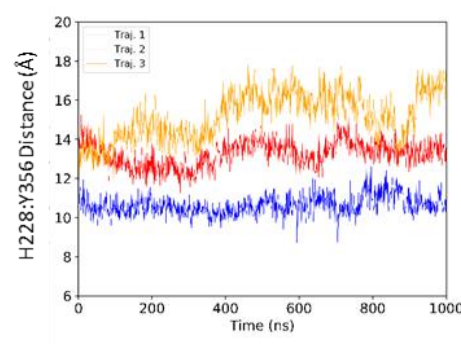 \\
\hline 6 & $\begin{array}{l}\text { N312 } 2^{5.50}: \text { Y356 } \\
\text { (Center of Mass) }\end{array}$ & 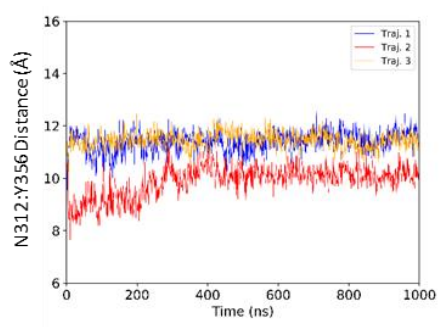 & 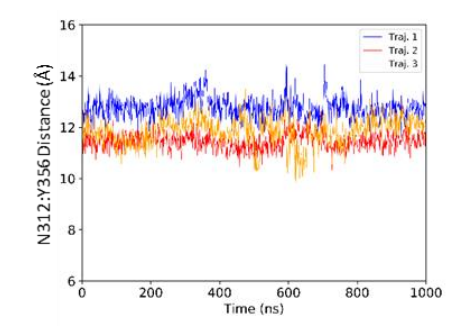 \\
\hline
\end{tabular}




\begin{tabular}{|c|c|c|c|}
\hline 7 & $\begin{array}{c}\mathrm{R} 180^{2.46}: \mathrm{E} 398^{\mathrm{H} 8} \\
(\mathrm{~N}---\mathrm{O})\end{array}$ & 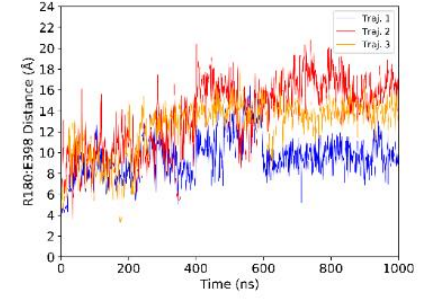 & 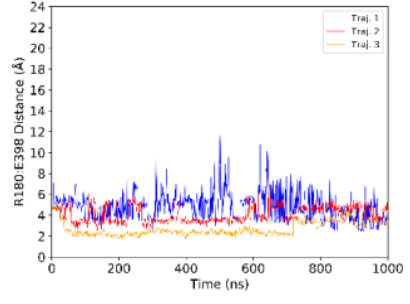 \\
\hline 8 & $\begin{array}{c}\text { D156 }{ }^{1.76}: \mathrm{R} 194^{2.60} \\
(\mathrm{~N}---\mathrm{O})\end{array}$ & 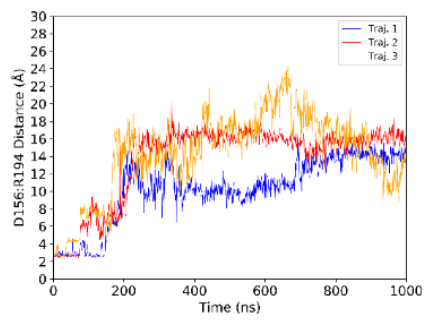 & 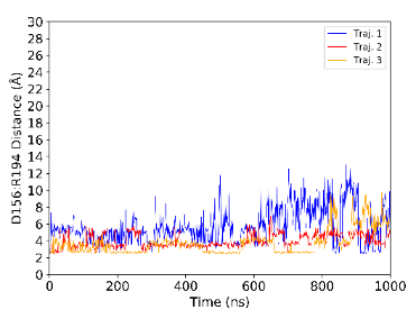 \\
\hline 9 & $\begin{array}{c}\mathrm{D} 283^{4.68}: \mathrm{R} 292^{\mathrm{ECL} 2} \\
(\mathrm{O}---\mathrm{N})\end{array}$ & 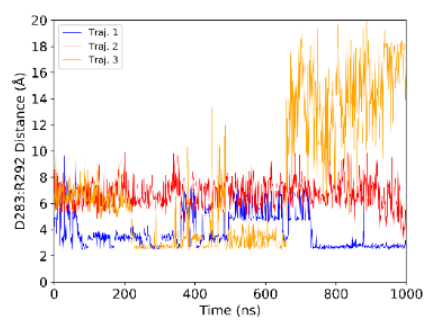 & 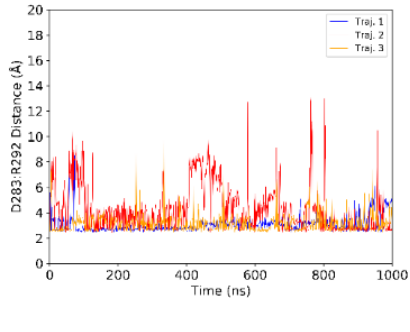 \\
\hline 10 & $\begin{array}{c}\text { E285 } 5^{7.50}: \mathrm{R}_{292} 2^{\mathrm{ECL} 2} \\
(\mathrm{O}---\mathrm{N})\end{array}$ & 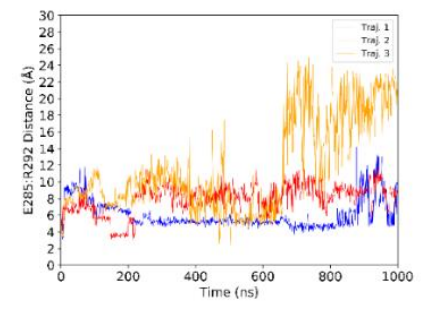 & 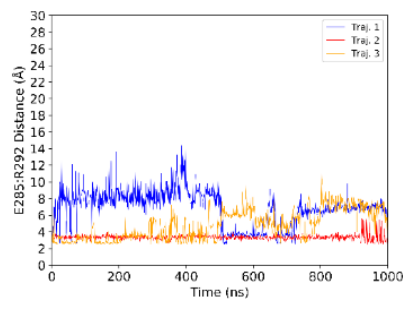 \\
\hline 11 & $\begin{array}{c}\text { K291 } \\
\left(\mathrm{NCL} 2: \mathrm{D} 298^{5.36}\right. \\
\end{array}$ & 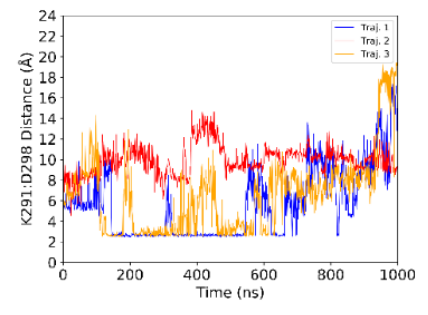 & 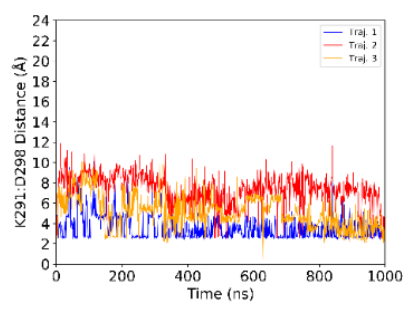 \\
\hline
\end{tabular}




\begin{tabular}{|c|c|c|c|}
\hline 12 & $\begin{array}{c}\mathrm{D} 366^{\mathrm{ECL3}}: \mathrm{R} 370^{7.35} \\
(\mathrm{O}---\mathrm{N})\end{array}$ & 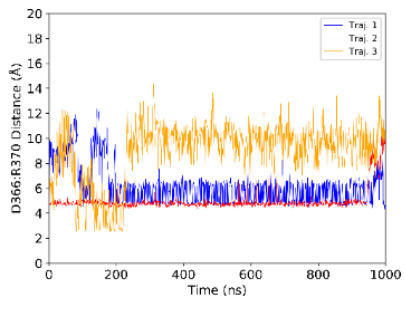 & 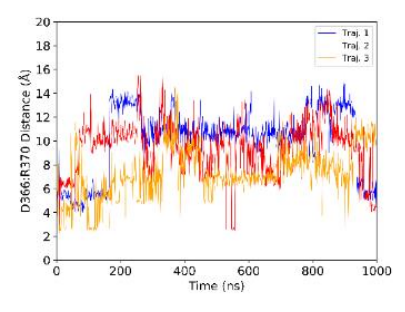 \\
\hline 13 & $\begin{array}{c}\mathrm{E} 208^{\mathrm{ECL} 1}: \mathrm{K} 286^{\mathrm{ECL} 2} \\
(\mathrm{O}---\mathrm{N})\end{array}$ & 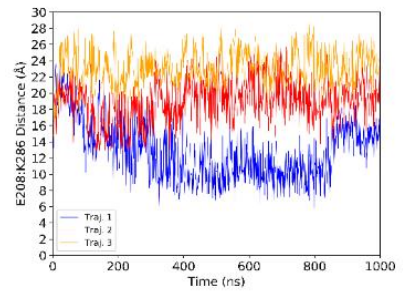 & 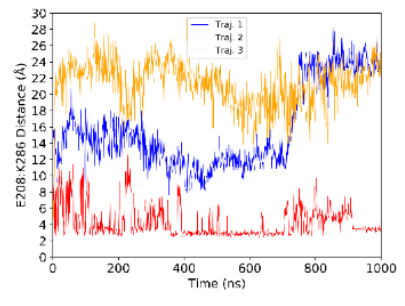 \\
\hline 14 & $\begin{array}{c}\mathrm{R} 218^{3.30}: \mathrm{E} 285^{\mathrm{ECL} 2} \\
(\mathrm{~N}---\mathrm{O})\end{array}$ & 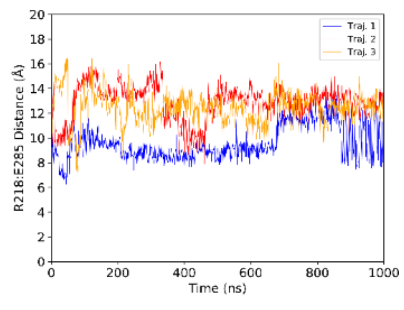 & 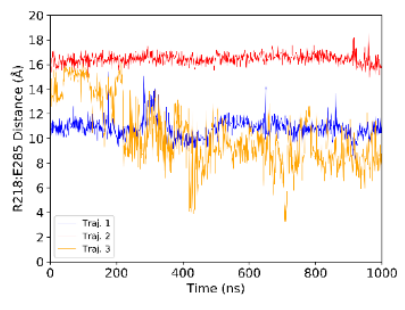 \\
\hline 15 & $\begin{array}{l}\text { R173 }{ }^{\text {ICL1}: E 398^{\mathrm{H} 8}} \\
(\mathrm{~N}---\mathrm{O})\end{array}$ & 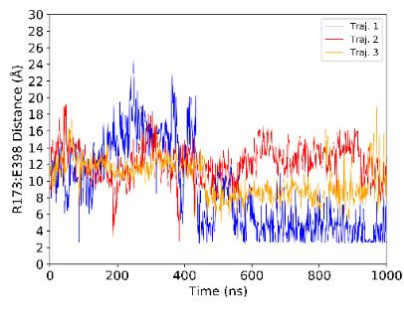 & 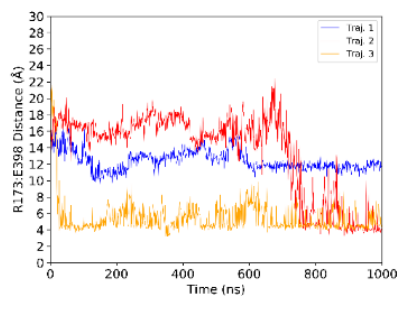 \\
\hline 16 & $\begin{array}{c}\text { K291 } \\
(\mathrm{N}---\mathrm{EC} 2 \cdot \mathrm{O})\end{array}$ & 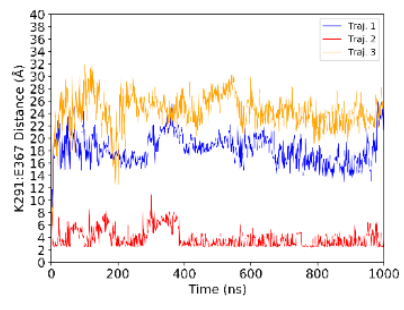 & 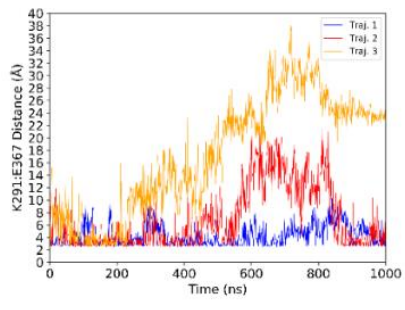 \\
\hline
\end{tabular}




\begin{tabular}{|c|c|c|c|}
\hline 17 & $\begin{array}{l}\mathrm{R} 194^{2.60}: \mathrm{E} 381^{7.46} \\
(\mathrm{~N}---\mathrm{O})\end{array}$ & 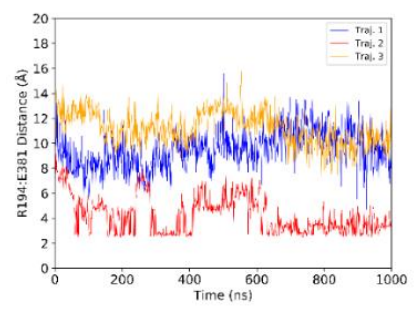 & 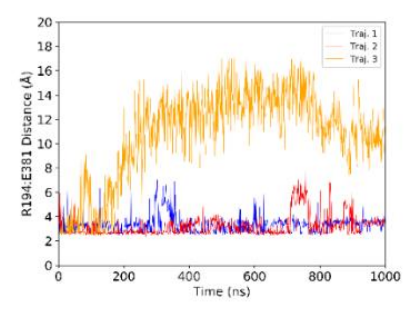 \\
\hline 18 & $\begin{array}{c}\text { E160 } 0^{1.76}: \mathrm{N} 195^{2.61} \\
(\mathrm{O}---\mathrm{NH})\end{array}$ & 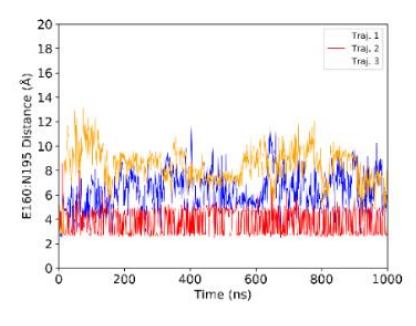 & 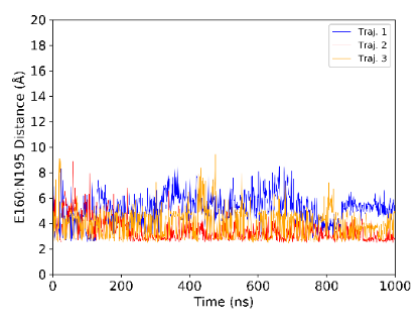 \\
\hline 19 & $\begin{array}{c}\mathrm{D} 156^{1.76}: \mathrm{Q} 202^{2.68} \\
(\mathrm{O}---\mathrm{NH})\end{array}$ & 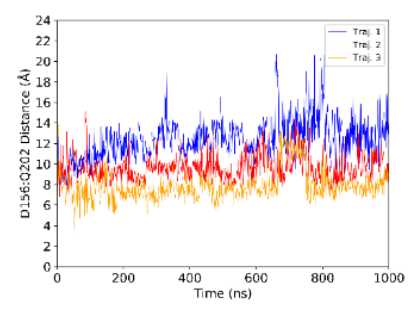 & 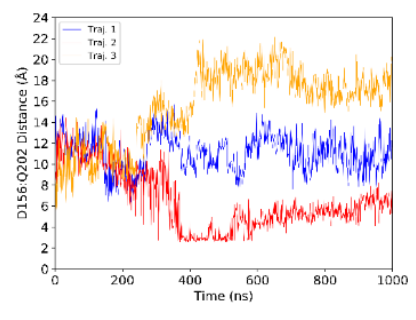 \\
\hline 20 & $\begin{array}{c}\text { Y356 } 6^{6.53}: \text { Q384 } \\
(\mathrm{OH}--\mathrm{-N})\end{array}$ & 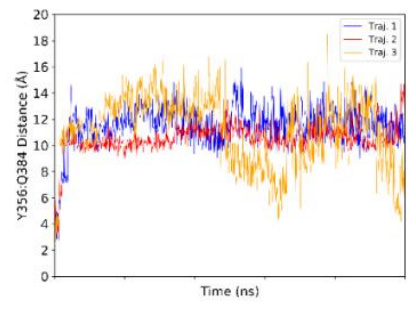 & 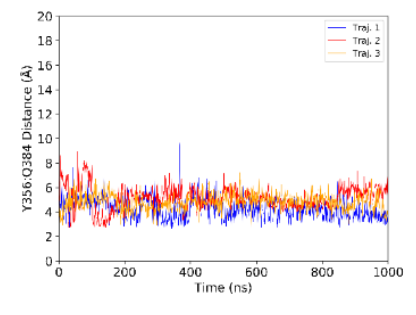 \\
\hline 21 & $\begin{array}{c}\mathrm{N} 362^{\mathrm{ECL} 3}: \mathrm{R} 370^{7.35} \\
(\mathrm{NH}---\mathrm{N})\end{array}$ & 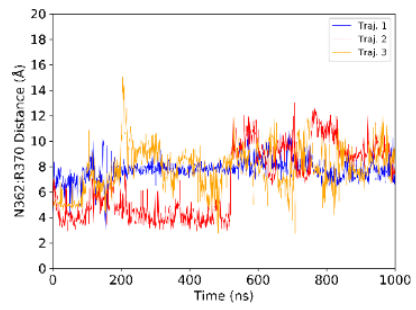 & 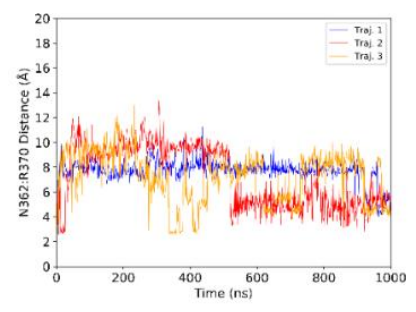 \\
\hline
\end{tabular}

Figure S14. Residue distance for molecular switches (1-3), and for remote residues in antagonist binding site (4-6) examined in the literature [6, 26]. Potential interhelical salt bridges (7-17) and side chain-side chain H-bonds (18-21) examined in this study. R180 $2.46, \mathrm{H} 184^{2.50}$, E238 $38^{3.50}$ and Q3847.49 are $83 \%$ conserved in class B and subfamily B 1 of class B GPCRs. R194 2.60 , Y356 $6^{6.53}$, and $\mathrm{E} 398^{\mathrm{H} 8}$ are $66 \%, 72 \%$, and $83 \%$ conserved, respectively, in subfamily B 1 of class B GPCRs. 


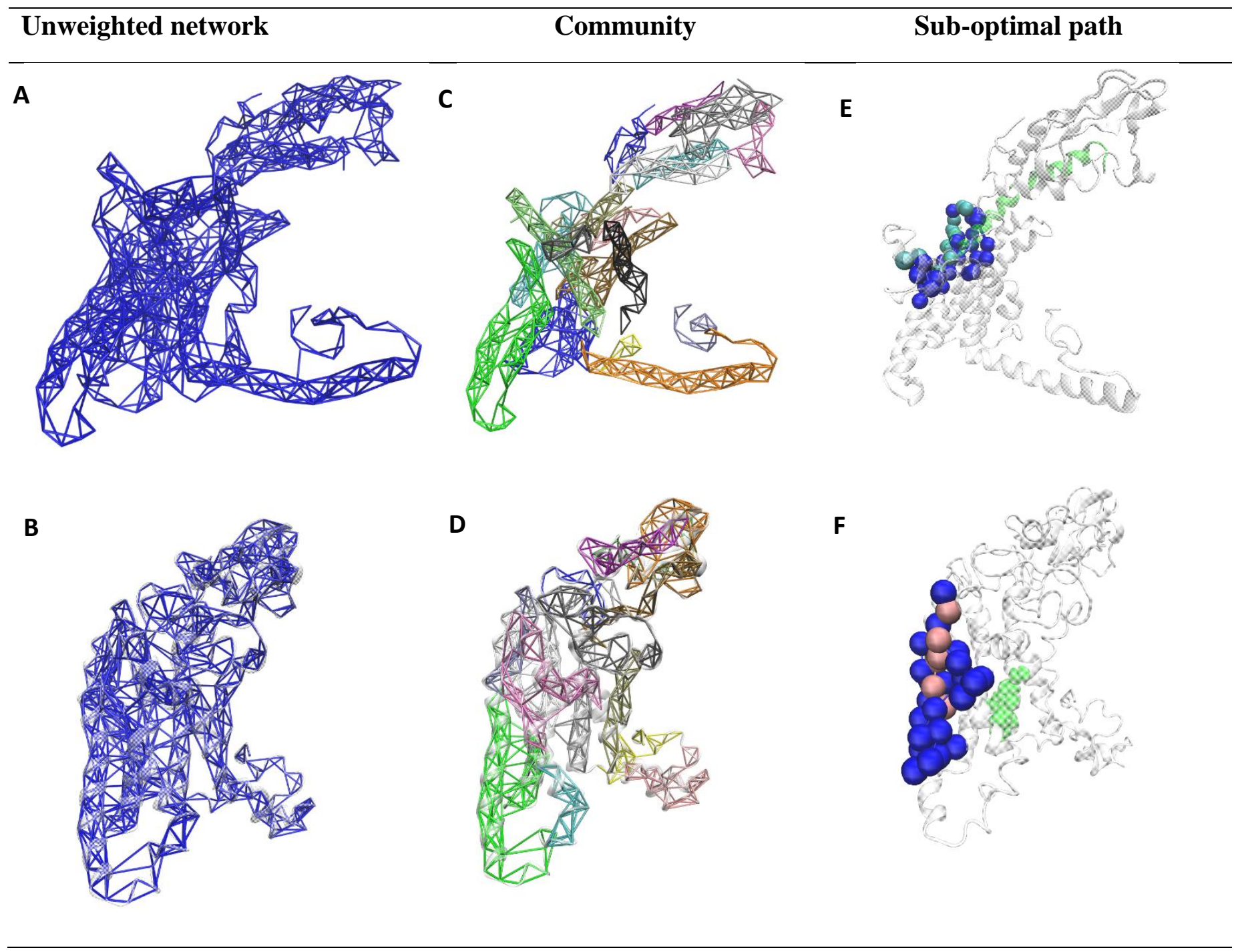

Figure S15. Agonist urocortin 1 bound CRF1R versus antagonist CP-376395 bound CRF1R system: (A vs B) unweighted network; (C vs D) communities; and (E vs F) suboptimal paths. 
A

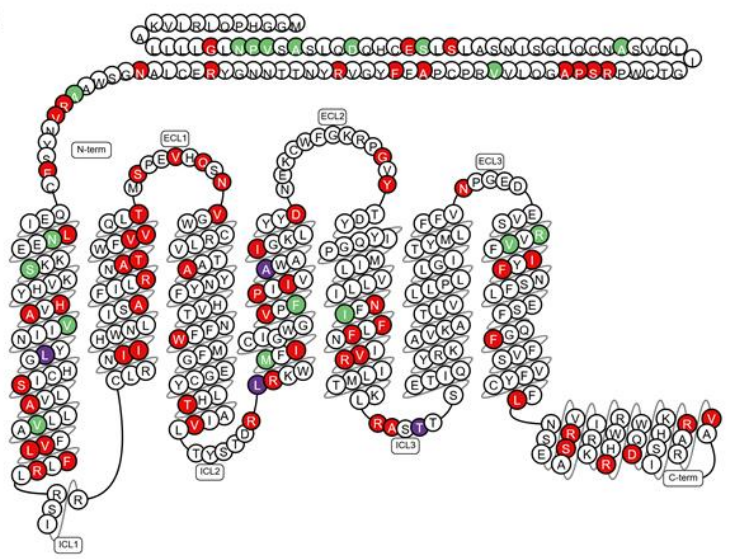

C

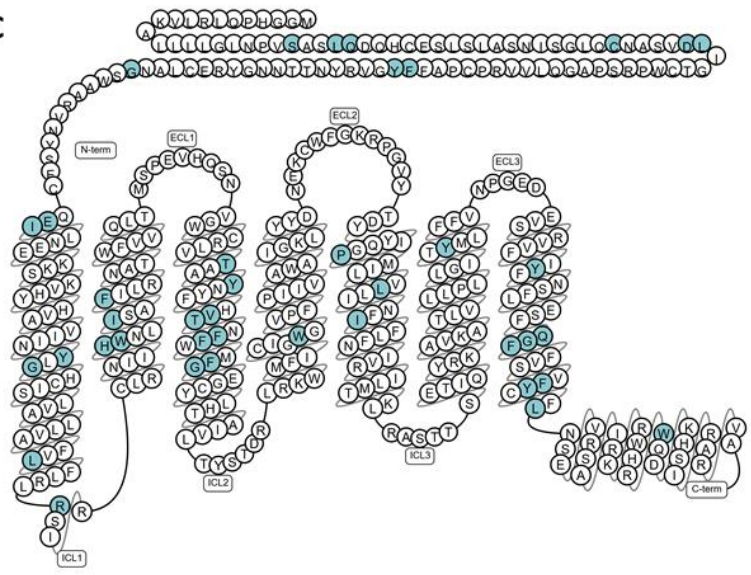

$\mathbf{E}$

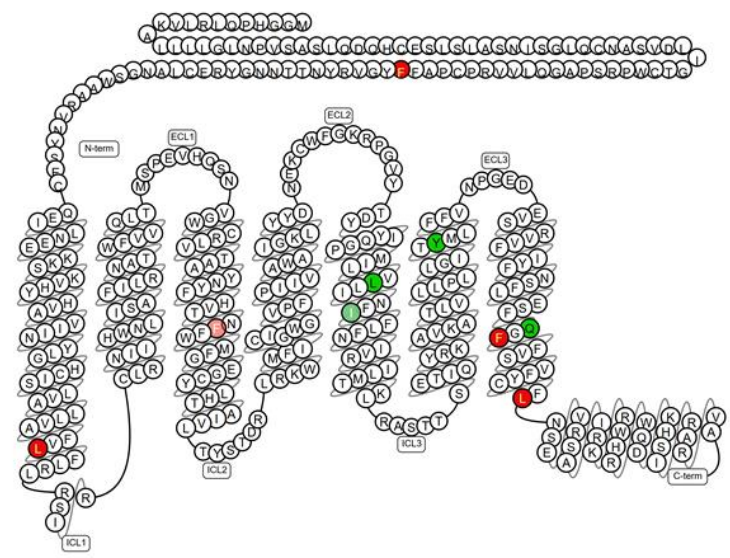

B

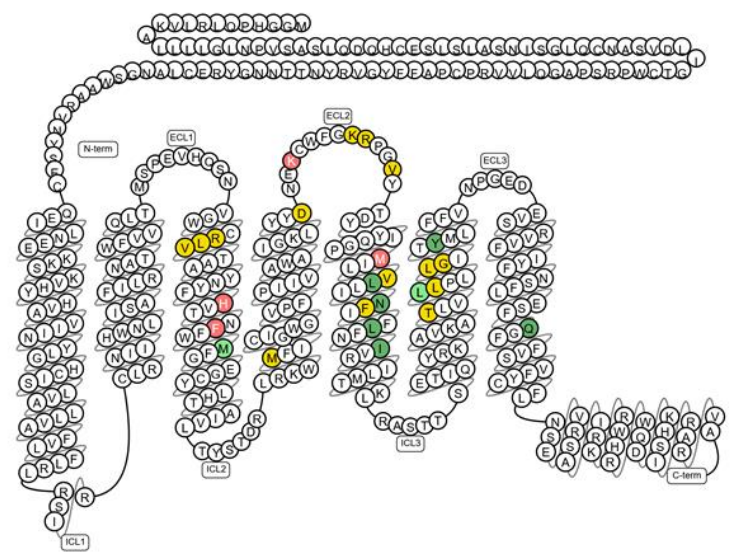

D

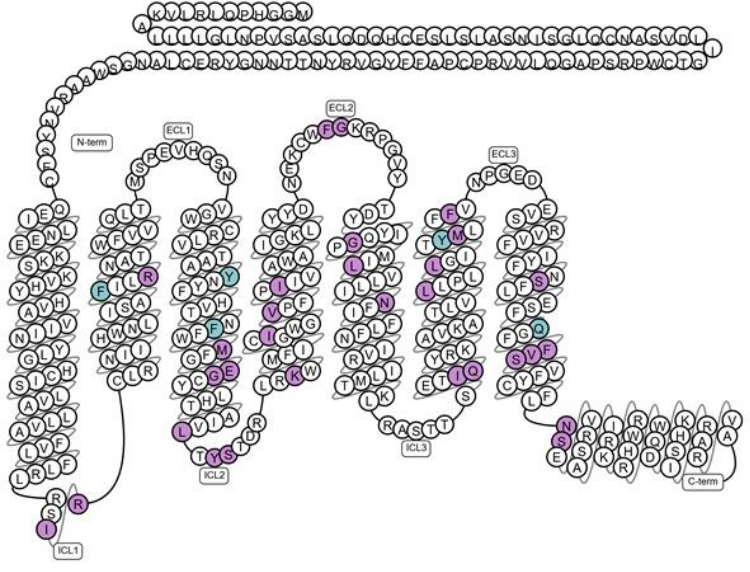

F

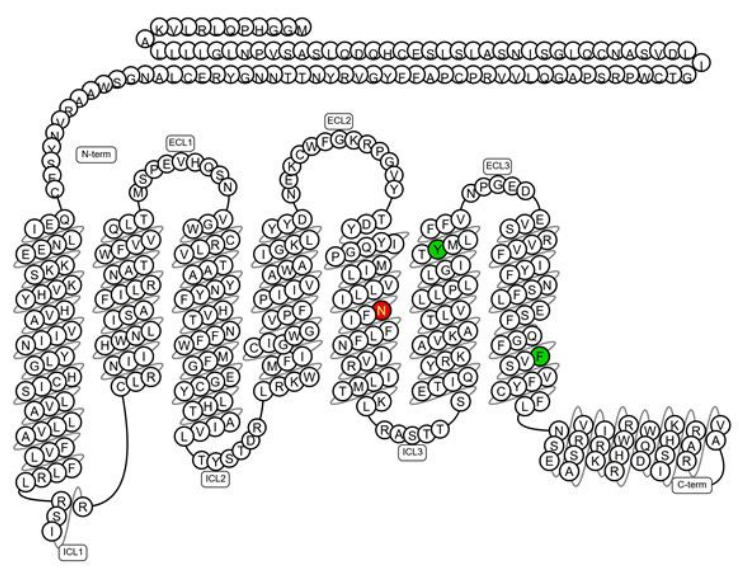

Figure S16. Cross-referencing critical nodes with mutagenesis data: (A) natural genetic variation (deleterious; deleterious; tolerated) ; (B) in vitro Mutation (Increased binding/potency: $>5$-fold, $>10$-fold; reduced binding/potency: $>5$-fold, $>10$-fold; no/low effect ( $<5$-fold); and N/A). (C) Critical nodes identified in the agonist urocortin 1 bound CRF1R. (D) Critical nodes identified in the antagonist CP-376395 bound CRF1R. (E) Critical nodes identified in the agonist urocortin 1 bound CRF1R that overlap with the mutagenesis data. (F) Critical nodes identified in the antagonist CP-376395 bound CRF1R that overlap with the mutagenesis data. 


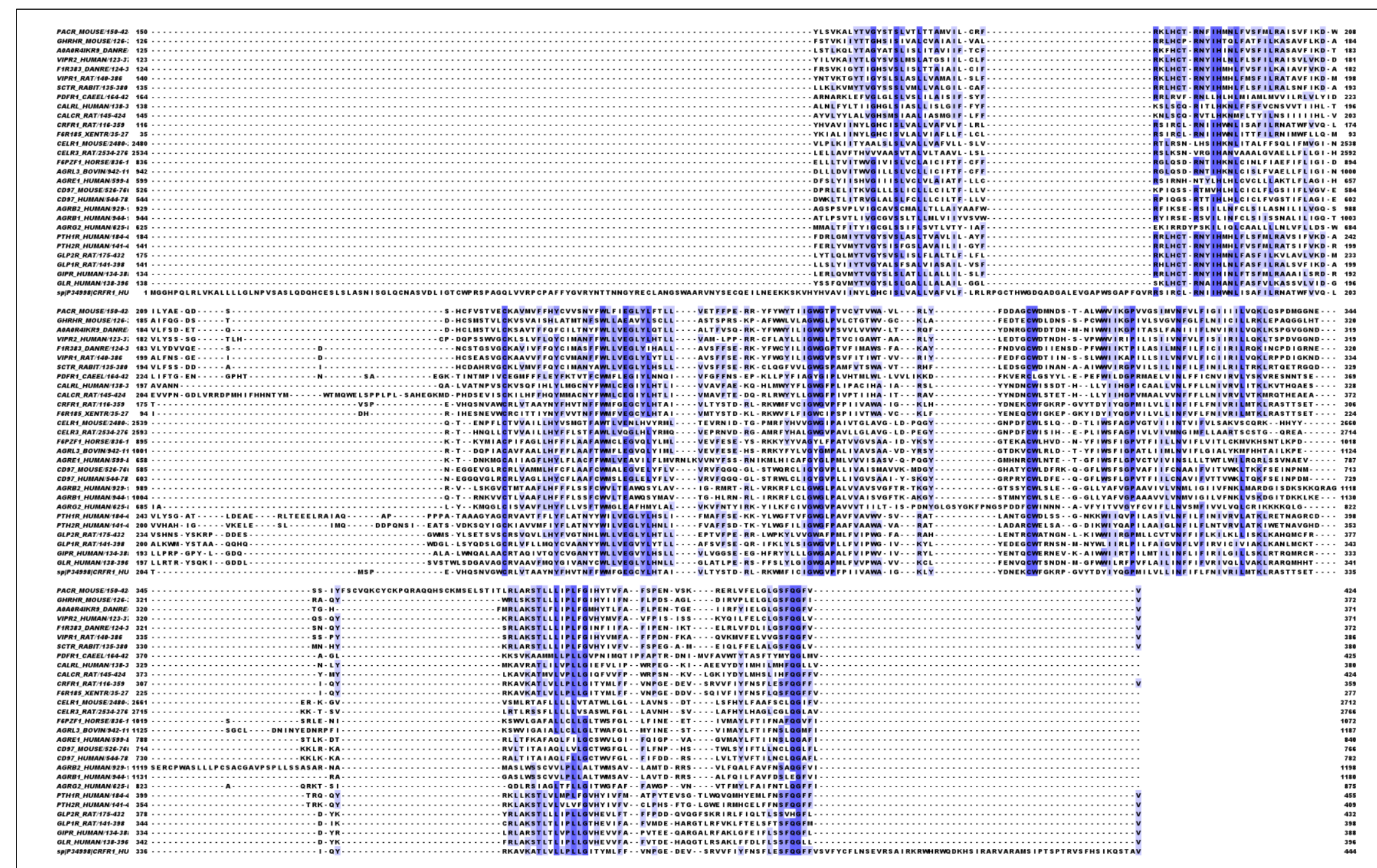

Figure S17. Multiple sequence alignment of PFAM SEED sequence of class B GPCRs with human CRF1R: intensity of coloration indicates quality of the alignment. 


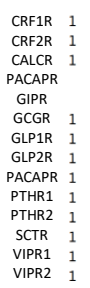

CRF1R 37 $\begin{array}{ll}\text { CRF2R } & 35 \\ \text { CALCR } & 64\end{array}$

PACAPR

GIPR

$\begin{array}{lll}\text { GCGR } & 5 \\ \text { GLP1R } & 5\end{array}$

GLPIR 5

$\begin{array}{ll}\text { PACAPR } & 49 \\ \text { PTHR1 } 57 & \end{array}$

PTHR2 57

$\begin{array}{ll}\text { SCTR } & 54 \\ \text { VIPR1 } & 58\end{array}$

VIPR2 46

CRF1R 91

$\begin{array}{lr}\text { CRF2R } & 87 \\ \text { CALCR } & 116\end{array}$

PACAPR 1

$\begin{array}{lr}\text { GIPR } & 1 \\ \text { GCGR } & 104\end{array}$

GLP1R 108

GLP2R 141

PACAPR 100

$\begin{array}{ll}\text { PTHR1 } & 152 \\ \text { PTHR2 } & 107\end{array}$

SCTR 111

$\begin{array}{lr}\text { VIPR1 } & 109 \\ \text { VIPP2 } & 97\end{array}$

$\begin{array}{cr} & \\ \text { CRF1R } & 177 \\ \text { CRF2R } & 145 \\ \text { CALCR } & 177 \\ \text { PACAPR } & 33 \\ \text { GIPR } & 26 \\ \text { GCGR } & 170 \\ \text { GLP1R } & 173 \\ \text { GLPR } & 207 \\ \text { PACAPR } & 158 \\ \text { PTHR1 } & 216 \\ \text { PTHR2 } & 173 \\ \text { SCTR } & 171 \\ \text { VIPR1 } & 171 \\ \text { VIPR2 } & 155\end{array}$

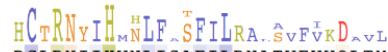

G.W....WS G SWAARVNYSECQEI LNE EKKSKVHYHVAVI INYLGHCISLVALLVAFVLFLRLRPGCTHWGDQADGALEVGAPWSGAPFQVRRS 176

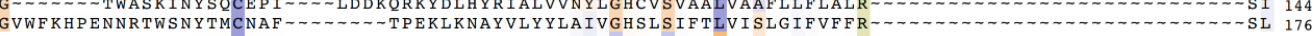

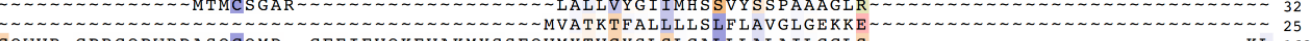

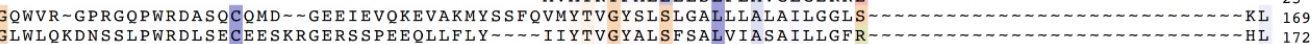

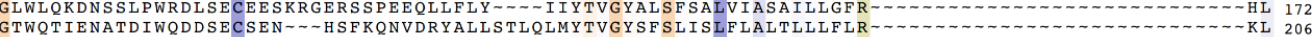

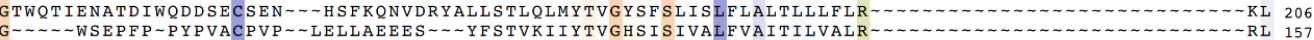
GSWE LVPGHNRTWANY SECVKF $\sim \sim$ L TNET T REREVFDRLGMIY TVGYSVSLASLTVAVLILAYFR RL 215 G

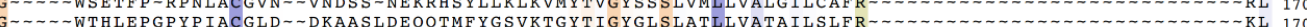

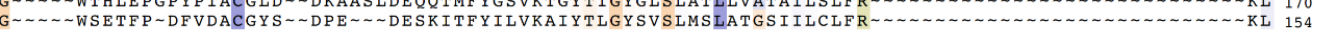

100 응

$64 \%$
218

58
38

$23 \%$

188

25 웅

$19 \%$

258

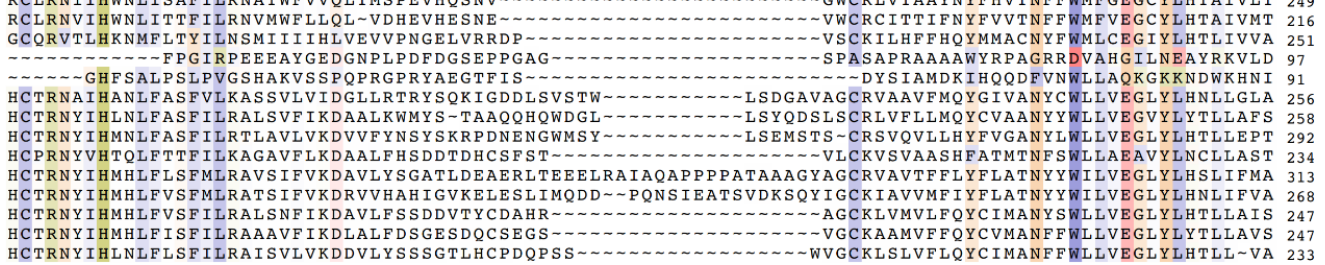

1008

648

218
58
38

38
$23 \%$

228

$18 \%$
$25 \%$

208

$25 \%$
248

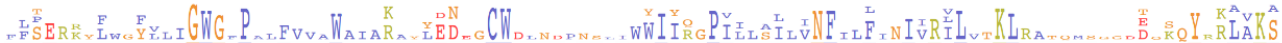

CRF1R 250 YSTDRLRKWMFICIGWGVPFPIIVAWAIGKLYYDNEKCWFGRRPGVYTDYIYQGPMILVLLINFIFLFNIVRILMTKLRASTTS ETIQYRKAVKA 344 CRF2R 217 YSTERLRKCLFLFIGWCIPFPIIVAWAIGKLYYENEQCWFGKEPGDLVDYIYQGPIILVLLINFVFLFNIVRILMTKLRASTTS ETIQYRKAVKA 311 CALCR 252 VFTEK QRLRWYYLLGWGFPLVPTTIHAITRAVYFNDNCWLSVE THLLYIIHGPVMAALVVNFFFLLNIVRVLVTKMRETHEA ESHMYLKAVKA 344 PACAPR 98 QLSAGKHLQSLVARGVGG SLGGGAGDDAEPLSKRH SDGIFTDSYSRYRKQMAVKKYLAAVLG KRYKQRVKN 168

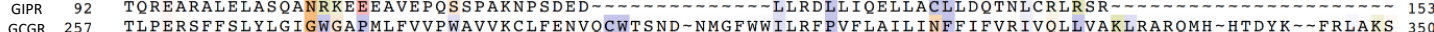
GCGR 257 TLPERSFF SLYLGIGWGAPMLFVVPWAVVKCLFENVQCWTSND NMGFWW ILRFPVF LAILINFFIFVRIVQLLVAKLRARQMH HTDYK FRLAKS 350 GLP1R 259 VLSEQWIFRLYVIGWGVPLFVVPWGIVKYLYEDEGCWTRNS NMNYWLIIRLPILFAIGVNFLIFVRVICIVVSKLKANLMC KTDIK CRLAKS 352 PACAPR 235 PACAPR 235 PTHR2 269 SCTR 248 $\begin{array}{ll}\text { VIPR1 } & 248 \\ \text { VIPR2 } & 234\end{array}$ SPSSRRAFWWLVLAGWGLPVLFTGTWVSCKLAFEDIACWDLDD TSPYWWIIKGPIVLSVGVNFGLFLNIIRILVRKLEPAQGS LHTQSQYWRLSKS 330 FFSDTKYLWGF I I WWG PAAFVAAWAVARATLADARCWELS A D I KW IYOAPILAA IGLNF I L LNTVRVLATK IWETNAVGHDTRKOYRKLAKS 364 FFSERKY LOGFVAFGWGSPA I FVALWA I ARHF LEDVGCWDINA N AS I WW I IRGPVILS I L INF I LF IN I LR I LMRKLRTOETR GNEVSHYKRLARS 343

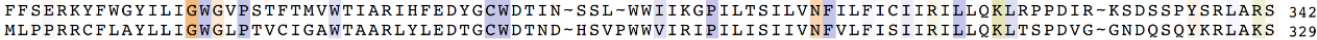




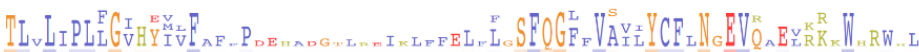

$\begin{array}{ll}\text { CRF1R } & 345 \\ \text { CRE2R } & 312\end{array}$

CRF2R 312

PACAPR 16

GIPR

GCGR 351

GLPIR 353

(T)ER 337

PTHP1 410

PTHR2 365

SCTR 344

VIPR2 330

LVLLPLLGITYMLFFVNPGE DEVSRVVFIYFNSFLESFOGFFVSVFYCFLNSEVRSAIRKRWHRWODKHS IRARVARAMSIPT 42 作

LTLIPLLGVHEVVFAFVTDEHAQGTLRSAKLFFDLFLSSFQGLLVAVLYCFLNKEVQSELRRRWHRWRLGK VLWEERNTSNHRA 435

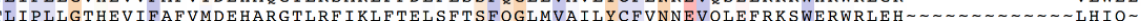
TLVLIPLLGVHE I LFSF I TDDQVEGFAKL IRLF I OLTLSSFHGF LVALOYGFANGEVKAE LRK Y WVRF LLARH SGCRACVLGKDFRFLGKCPKKLSEG 484 TLVMPLFGVHY IVFMATPYTEVSGTLWOVOMHYEMLFNSFOGFFVAI IYCFCNGEVOAEIKKSWSRWTLALDFKRKARS GSSSY SYGPMVSHT 503 LVLVLVFGVHY IVFVCLPHS FTGLGWEIRMHCELFFNSFOGFFVSIIYCYCNGEVOAEVKKMWSRWNLSVDWKRTPPC -GSRRCGSVLTTVTHS 458

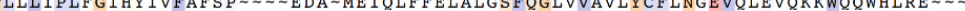

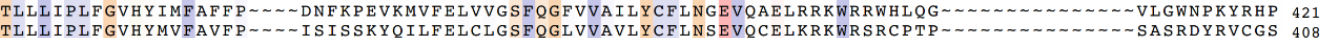

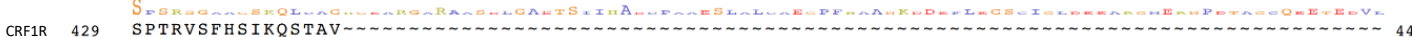

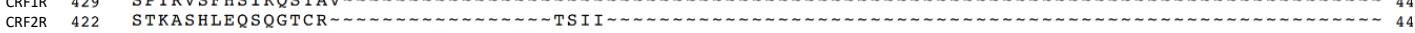

CALCR 422

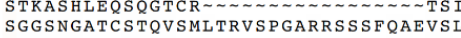

SFSRNGSEGALQFHR GSRAQSFLQTETSVI

Figure S18. Multiple sequence alignment of Subfamily B 1 of class B GPCRs. Residues are colored based on residue type: intensity of coloration indicates quality of the alignment. 
A

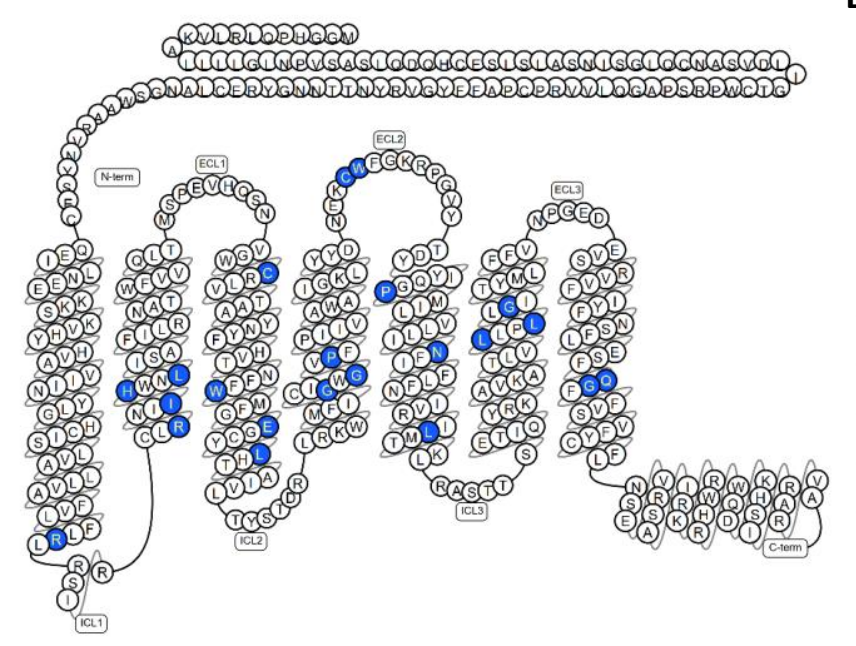

C

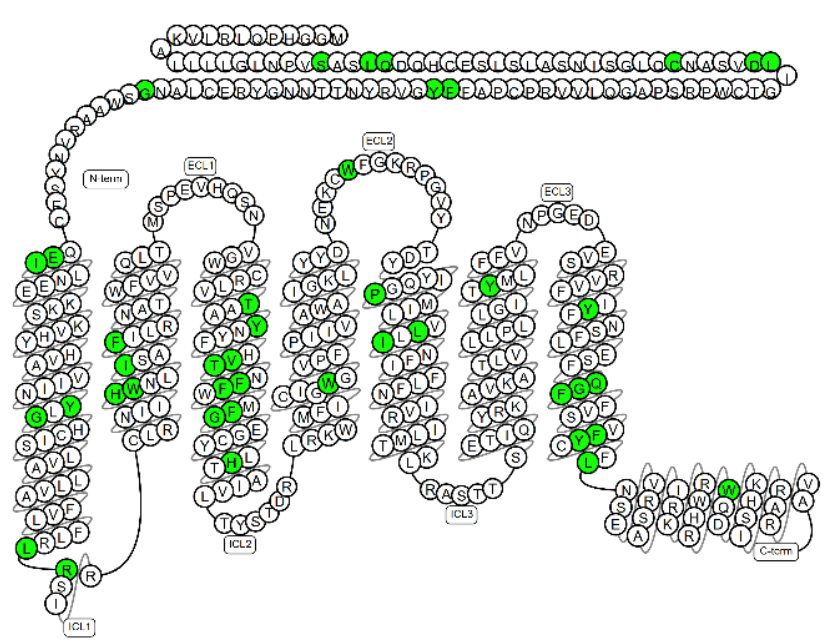

B

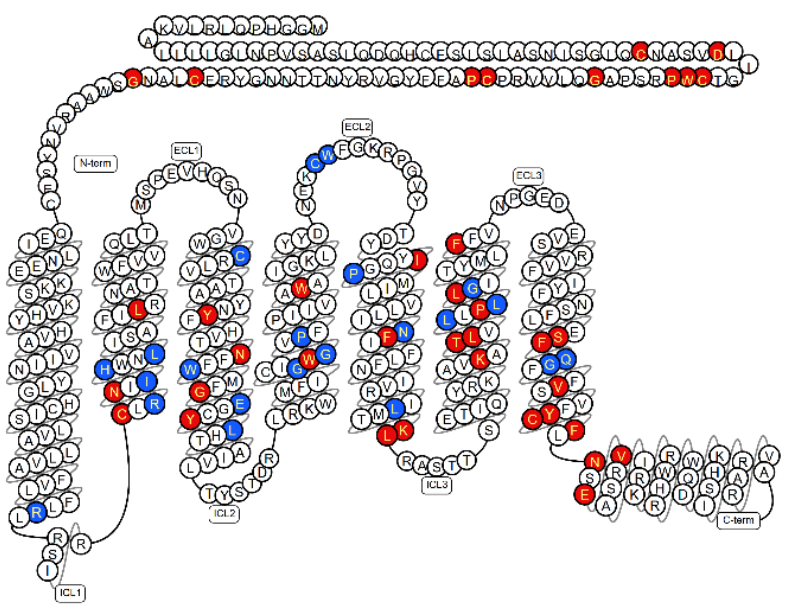

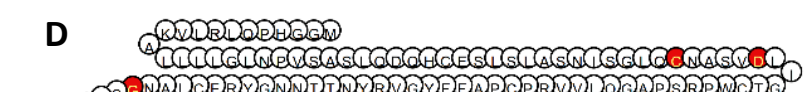

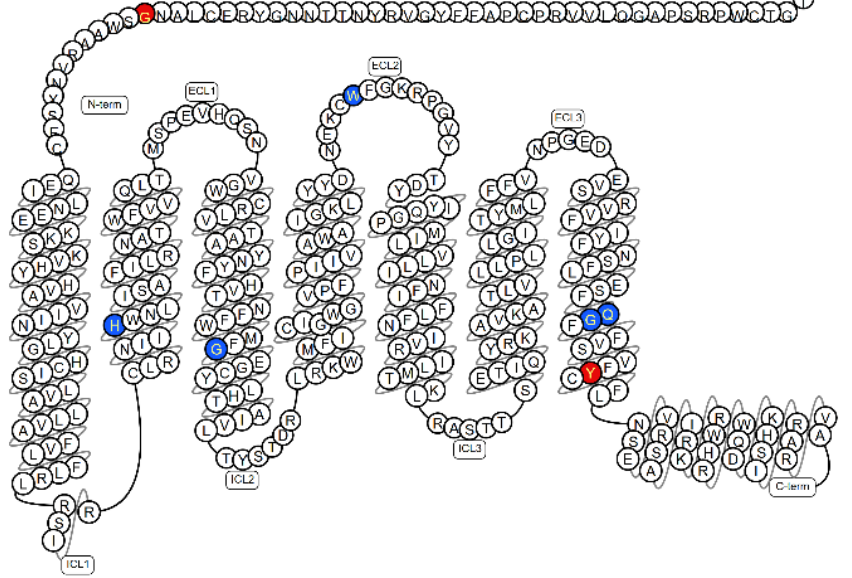

Figure S19. Cross-referencing conserved residues with critical nodes. (A) Conserved residues in class B (Blue) (B) and subfamily B 1 (blue and red) GPCRs. (C) Critical residues identified via dynamic network analysis. (D) Conserved residues that overlap with critical nodes. 
